\title{
Flow Simulation of N2B Hybrid Wing Body Configuration
}

\author{
Hyoungjin Kim* \\ ASRC Aerospace Corporation, Cleveland, $\mathrm{OH} 44135$ \\ and \\ Meng-Sing Liou $^{\dagger}$ \\ NASA Glenn Research Center, Cleveland, OH 44135
}

\begin{abstract}
The N2B hybrid wing body aircraft was conceptually designed to meet environmental and performance goals for the $\mathrm{N}+2$ generation transport set by the subsonic fixed wing project. In this study, flow fields around the N2B configuration is simulated using a Reynolds-averaged Navier-Stokes flow solver using unstructured meshes. Boundary conditions at engine fan face and nozzle exhaust planes are provided by response surfaces of the NPSS thermodynamic engine cycle model. The present flow simulations reveal challenging design issues arising from boundary layer ingestion offset inlet and nacelle-airframe interference. The N2B configuration can be a good test bed for application of multidisciplinary design optimization technology.
\end{abstract}

\section{Nomenclature}

$\begin{array}{ll}\text { ADP } & =\text { Aerodynamic Design Point } \\ \text { AIP } & =\text { Aerodynamic Interface Plane } \\ \text { BLI } & =\text { Boundary Layer Ingestion } \\ \text { BPR } & =\text { Bypass Ratio } \\ \text { HWB } & =\text { Hybrid Wing Body Aircraft } \\ \text { ISA } & =\text { International Standard Atmosphere } \\ \text { LTO } & =\text { Landing and take off } \\ \text { NPSS } & =\text { Numerical Propulsion System Simulation } \\ \text { OML } & =\text { Outer Mold Line } \\ \text { OPR } & =\text { Overall pressure ratio } \\ \text { RTO } & =\text { Rolling Take off } \\ \text { SFC } & =\text { Specific fuel consumption } \\ \text { SFW } & =\text { Subsonic Fixed Wing } \\ \text { SLS } & =\text { Sea Level Static } \\ \dot{m} & =\text { Mass flow rate } \\ \mathrm{P}_{\mathrm{t}} & =\text { Total pressure } \\ \mathrm{T}_{\mathrm{t}} & =\text { Total temperature } \\ \mathrm{U} & =\text { Streamwise velocity magnitude } \\ \mathrm{U} & =\text { Streamwise velocity magnitude at a boundary layer edge } \\ \eta & =\text { mean total pressure recovery at fan face }\end{array}$

\footnotetext{
* Aerospace Engineer, Member AIAA

${ }^{\dagger}$ Senior Technologist, Associate Fellow AIAA
} 


\section{Introduction}

The Subsonic Fixed Wing (SFW) project of NASA Fundamental Aeronautics Program has focused on research of next generations of civil aircraft. For each time frame of near-, mid- and far-term periods, specific reduction goals in noise, emission, and fuel burn have been defined from the current state of the art of aviation technology. [1] (See Table 1), To achieve the aggressive goals especially for the $\mathrm{N}+2$ and $\mathrm{N}+3$ time frames, innovative design concepts in airframe and propulsion need to be explored.

Table 1. NASA subsonic fixed wing project goals.[1]

\begin{tabular}{|c|c|c|c|}
\hline \multirow{2}{*}{$\begin{array}{c}\text { TECHNOLOGY } \\
\text { BENEFITS* }\end{array}$} & \multicolumn{3}{|c|}{$\begin{array}{c}\text { TECHNOLOGY GENERATIONS } \\
\text { (Technology Readiness Level = 4-6) }\end{array}$} \\
\cline { 2 - 4 } $\begin{array}{c}\text { Noise } \\
\text { (cum margin rel. to Stage 4) }\end{array}$ & $-32 \mathrm{~dB}$ & N+2 (2020**) & -42 dB \\
\hline $\begin{array}{c}\text { LTO NOx Emissions } \\
\text { (rel. to CAEP 6) }\end{array}$ & $-60 \%$ & $-75 \%$ & $-71 \mathrm{~dB}$ \\
\hline $\begin{array}{c}\text { Cruise NOx Emissions } \\
\text { (rel. to 2005 best in class) }\end{array}$ & $-55 \%$ & $-70 \%$ & $-80 \%$ \\
\hline $\begin{array}{c}\text { Aircraft Fuel/Energy Consumption } \\
\text { (rel. to 2005 best in class) }\end{array}$ & $-33 \%$ & $-80 \%$ & $-60 \%$ \\
\hline
\end{tabular}

* Projected benefits once technologies are matured and implemented by industry. Benefits vary by vehicle size and mission. $\mathrm{N}+1$ and $\mathrm{N}+3$ values are referenced to a 737-800 with CFM56-7B engines, N+2 values are referenced to a 777-200 with GE90 engines

** ERA's time-phased approach includes advancing "long-pole" technologies to TRL 6 by 2015

$\neq \mathrm{CO}_{2}$ emission benefits dependent on life-cycle $\mathrm{CO}_{2 \mathrm{e}}$ per $\mathrm{MJ}$ for fuel and/or energy source used

The hybrid wing body (HWB) aircraft, although not new, is an alternative design concept to the conventional tube-and-wing aircraft. [2] It has the fuselage and wings integrated into a flying wing, which has better aerodynamic efficiency than the tube-and-wing type configuration. Also, the wide airframe body of HWB configuration is beneficial for shielding downward-propagating noise from engines installed above the aircraft.

The Boeing Company studied HWB configurations meeting NASA SFW N+2 goals through a contract sponsored by NASA's Subsonic Fixed Wing (SFW) project of the Fundamental Aeronautics Program. [3] The "Silent Aircraft” SAX-40 [4, 5], a non-proprietary configuration was chosen as a starting point. Two HWB configurations were considered in the study; one is the N2A model employing conventional podded engines and the other is the N2B model, which uses embedded engines and boundary layer ingestion (BLI) offset inlets. The SAX-40, N2A and N2B configurations are illustrated in Fig.1. Figure 2 shows the embedded engine having three fans and the variable area thrust vectoring/reversing nozzle concept adopted in N2B. Compared to conventional pylon-mounted engines, embedded engines with BLI offset inlets allow reduced ram drag, wetted area, structural weight, and noise. Disadvantages of the embedded engines are higher flow distortion and reduced pressure recovery at engine faces due to the BLI offset inlet.

Owing to its nature of tightly coupled disciplines, the N2B configuration offers an excellent test bed for conducting multidisciplinary analysis/design optimization, e.g., with inclusion of aerodynamics, propulsion, and acoustics. High fidelity CFD based analysis/design is essential for accurate performance evaluation/improvement of propulsion-airframe integration. In the present study, as a first step toward MDAO of the HWB configuration, we conducted flow simulations of the N2B configuration to understand effects of the propulsion-airframe integration on the flow field around the vehicle and the embedded engine.

The remainder of this paper is organized as follows. First, the N2B configuration is reviewed and response surfaces for thermodynamic cycle models of the embedded engine are generated. In Section 3, numerical approaches for the flow simulation are explained including the flow solver, mesh generation and boundary conditions. Simulation 
results for the N2B aircraft are illustrated in Section 4. Summary and conclusions are followed in Section 5. Finally, a validation study for the flow solver on a wind tunnel test case of a BLI offset inlet is presented in Appendix.

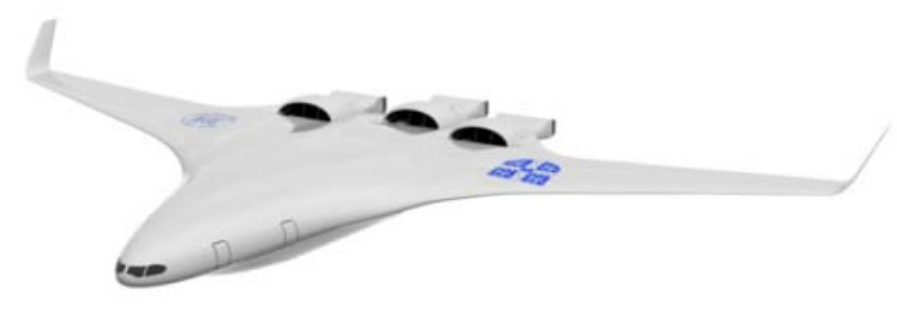

(a) SAX-40

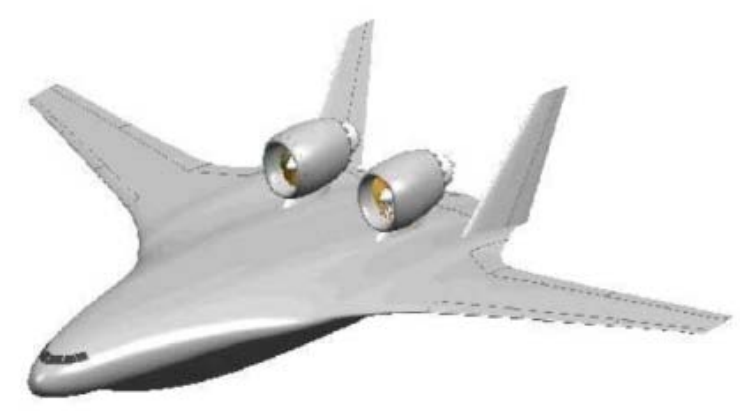

(b) N2A with podded engines

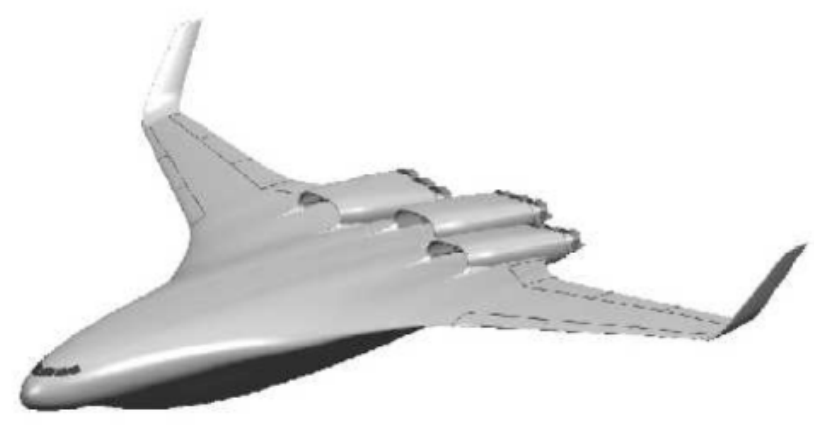

(c) N2B with embedded engines
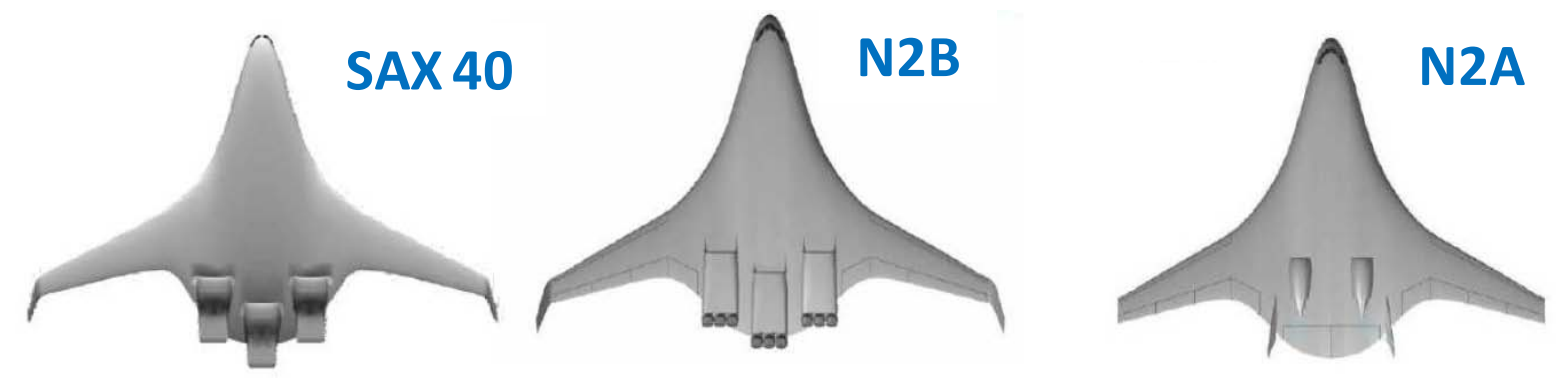

(d) Top view of the HWB aircrafts

Fig. 1 HWB aircraft configurations 


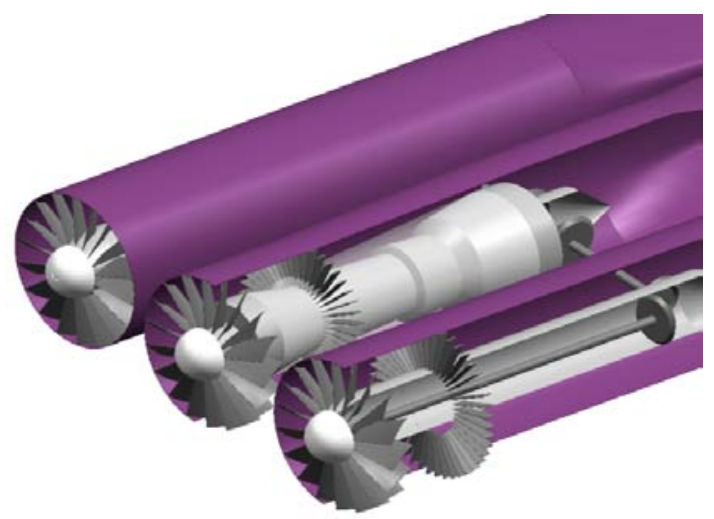

(a) Tri-fan + core engine

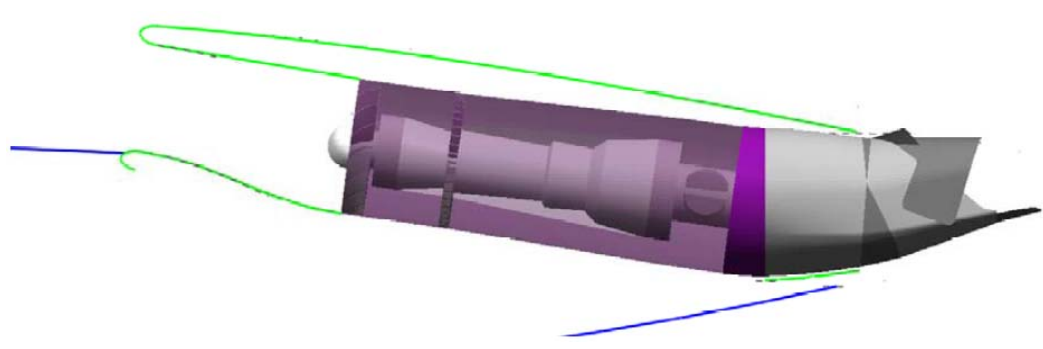

(b) Core engine + variable area thrust vectoring nozzle

Fig. 2. Multiple fan embedded turbofan engine for N2B. [3]

\section{N2B Hybrid Wing Body Aircraft}

\section{A. N2B design parameters [3]}

The N2B was suggested by Boeing as a cargo freighter aircraft and conceptually designed to have a $477,400 \mathrm{lb}_{\mathrm{m}}$ MTOGW, 103,000 lb $\mathrm{b}_{\mathrm{m}}$ payload and a 6,000 nm range. The cruise Mach number is 0.80 and initial cruise altitude is $35,000 \mathrm{ft}$. Time to climb 31,000 ft is 0.29 hour. The span length is $213 \mathrm{ft}$, and the reference area is $9246 \mathrm{ft}^{2}$. It has three engines, each of which has three fans and one core engine.

\section{B. Engine model}

Figure 3 shows the internal layout of the tri-fan embedded turbofan engine. The concept was based on the SAX-40 GRANTA engine.[5] Conceptual design of the embedded engine was conducted in NASA Glenn Research Center for 2020 technology level. [6] Each engine has a gas generator (core engine) which drives an inline fan and two additional outboard fans through a mechanical transmission system. The Aerodynamic Design Point (ADP) is Mach number 0.8 and height of 31,000ft. The required thrust per engine at ADP is $10,000 \mathrm{lb}$ at ISA +0 . The design fan pressure ratio is 1.50 at $\mathrm{ADP}$. All the fans are of the same diameter and rotate at the same speed. The design bypass ratio (BPR) of the core engine is 3.1 and overall effective BPR of the tri-fan engine is 11.3 at ADP. The fan face Mach number is 0.674. The engine thermodynamic cycle was designed using the NPSS (Numerical Propulsion System Simulation) program [7, 8] in the study of Ref. [6]. Some details of N2B embedded engine cycle information are given in Table 2. 


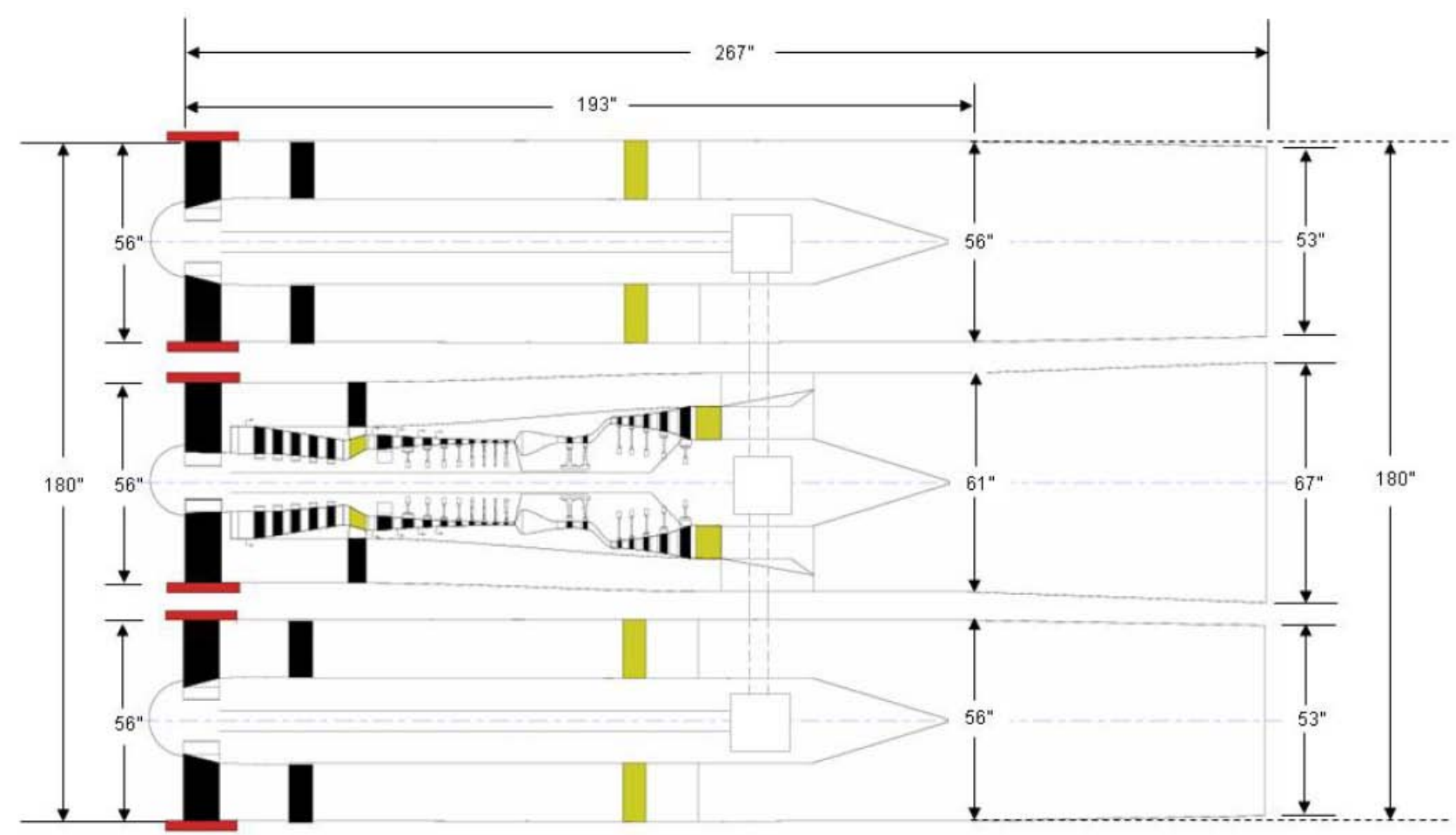

Fig.3 Internal layout of the imbedded engine.[6]

Table 2. NASA N2B embedded engine cycle information.[3]

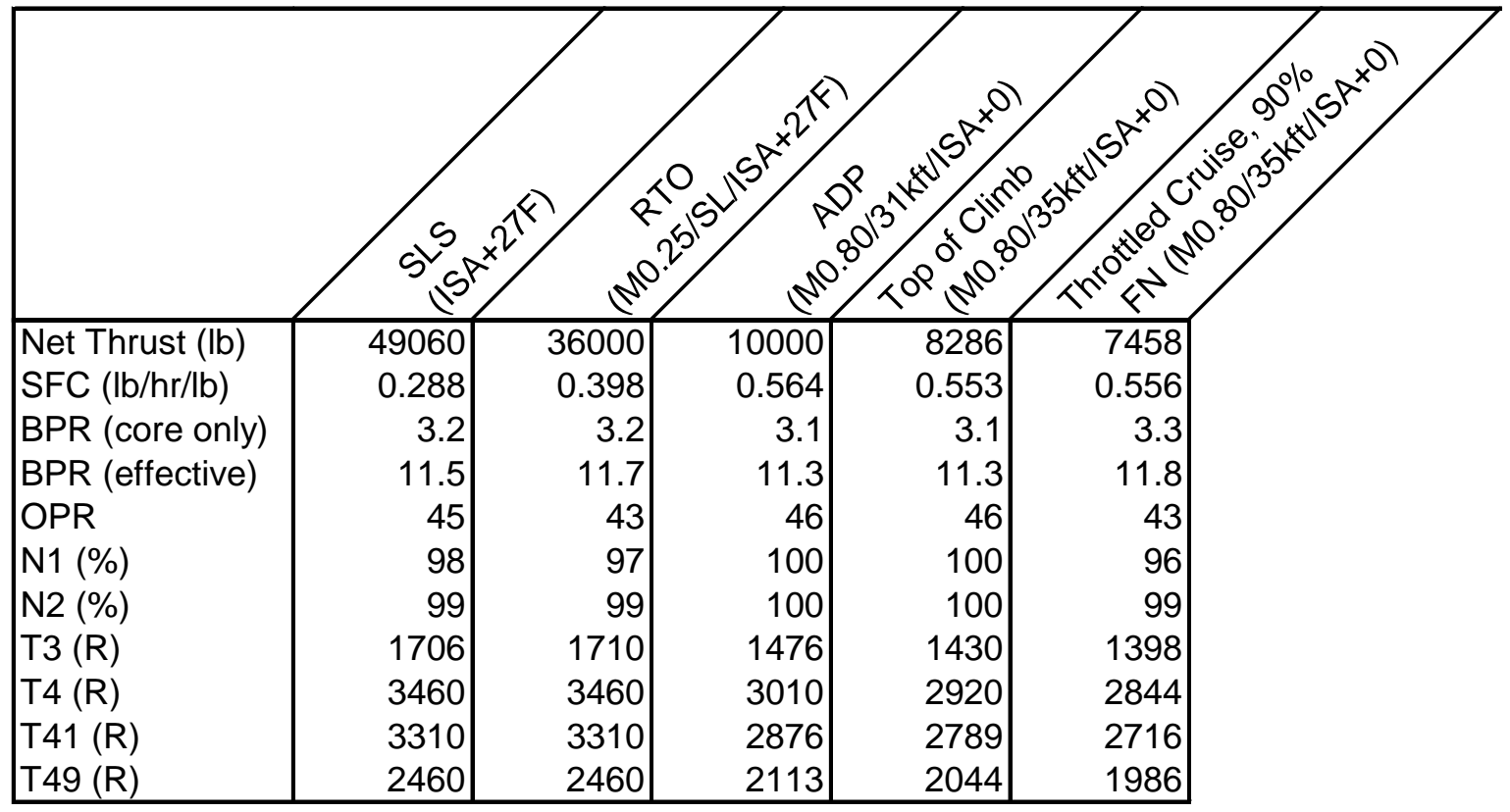

Total pressure recovery values at engine fan faces at ADP are estimated by Boeing from the mass averaged total pressure of the inlet capture flow at the inlet highlight using RANS flow analysis results on a clean wing configuration without engine installation assuming additional $0.6 \%$ total pressure loss inside the S-shaped inlet duct. [3] The recovery values are shown in Fig. 4 for three fan faces of the outer inlet. The center fan face recovery is composed of the bypass recovery of 0.96705 and the core recovery of 1.00 assuming that uncontaminated flow is fed into the core engine, while the boundary layer flow is ingested into the two side fans and bypass duct of the central passage. The engine thermodynamic cycle design was conducted based on the recovery values at ADP. 


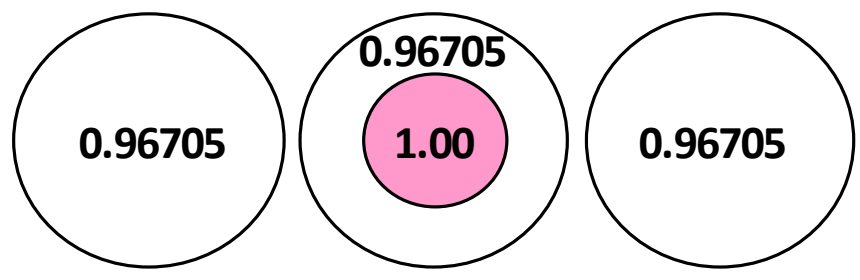

Fig. 4 Input values of pressure recovery for engine thermodynamic cycle design at ADP.

In the present study for computational fluid dynamics simulations of the N2B configuration, the embedded turbofan engines are replaced with an NPSS engine model as illustrated in Fig.5. Total pressure recoveries at engine fan faces are calculated by CFD and provided to the NPSS model and engine boundary conditions required for CFD analysis are obtained from the NPSS model as shown in Fig.5(c).

In the flow simulation, an engine fan face is treated as a subsonic exit boundary condition with specified target mass flow rates and a nozzle exhaust plane is treated as a subsonic inflow boundary condition with specified total conditions and a mass flow rate.

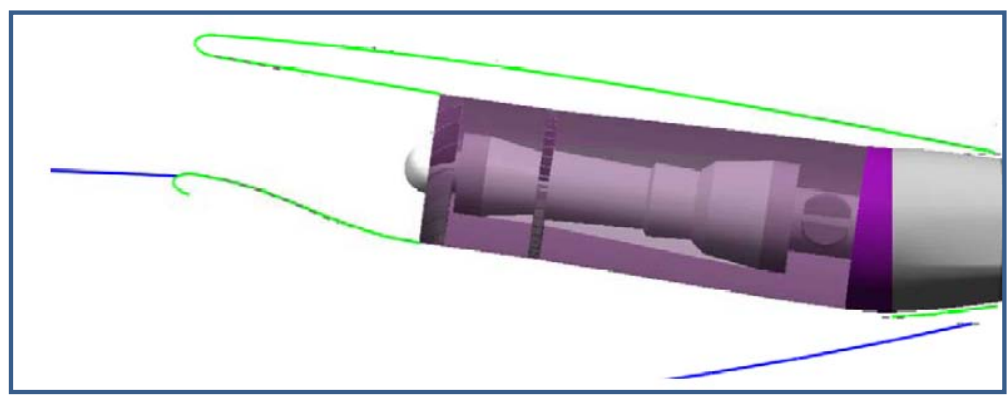

(a) Section view of the embedded engine core path.

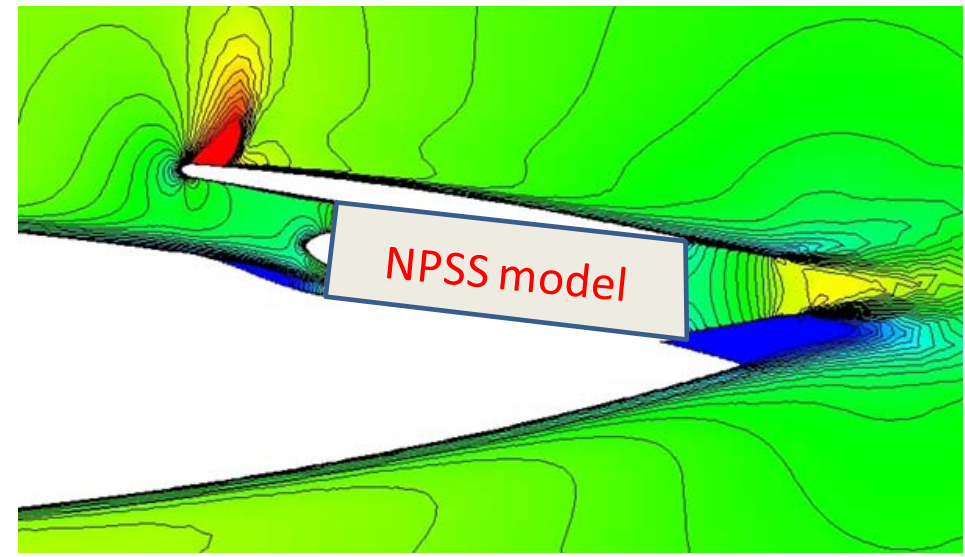

(b) Replacement of the engine with NPSS model.

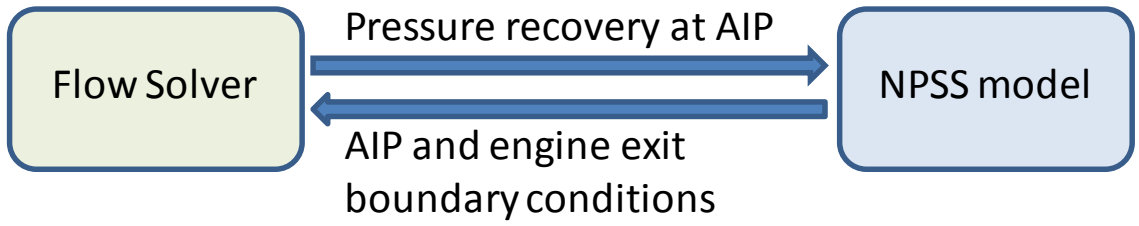

(c) Coupling of flow solver and NPSS model.

Fig. 5. Engine boundary conditions by NPSS model. 
In actual implementation, the coupling of the NPSS model with the flow solver can be made in a direct way by integrating the flow solver with the NPSS program via a script file for exchanging data of the two codes. An alternative choice is to build algebraic response surface models for the engine cycle and inserting the algebraic models into the flow solver. [9] In the present study, we employ the response surface approach for simplicity of the coupling. Accuracy of the coupling is not affected by the response surface approach because the behavior of the NPSS engine cycle model can be fitted very accurately by simple algebraic equations as will be shown later.

Engine parameters required for the present flow simulations are mass flow rate $\dot{m}$, total pressure $P_{t}$, total temperature $T_{t}$ at the nozzle exit of each flow passage. Input variables to the NPSS model are total pressure recoveries $\eta$ at fan faces. There are three input variables; $\eta_{1}, \eta_{2}, \eta_{3}$, for passages 1 (center passage), 2 and 3 (two side passages), respectively. If all the variables are independent and coupled together, we need nine functions, each of which is a function of the three input variables $\eta_{1}, \eta_{2}, \eta_{3}$ :

$$
\begin{aligned}
& \dot{m}_{1}=f_{m 1}\left(\eta_{1}, \eta_{2}, \eta_{3}\right), P_{t 1}=f_{P 1}\left(\eta_{1}, \eta_{2}, \eta_{3}\right), T_{t 1}=f_{T 1}\left(\eta_{1}, \eta_{2}, \eta_{3}\right) \\
& \dot{m}_{2}=f_{m 2}\left(\eta_{1}, \eta_{2}, \eta_{3}\right), P_{t 2}=f_{P 2}\left(\eta_{1}, \eta_{2}, \eta_{3}\right), T_{t 2}=f_{T 2}\left(\eta_{1}, \eta_{2}, \eta_{3}\right) \\
& \dot{m}_{3}=f_{m 3}\left(\eta_{1}, \eta_{2}, \eta_{3}\right), P_{t 3}=f_{P 3}\left(\eta_{1}, \eta_{2}, \eta_{3}\right), T_{t 3}=f_{T 3}\left(\eta_{1}, \eta_{2}, \eta_{3}\right)
\end{aligned}
$$

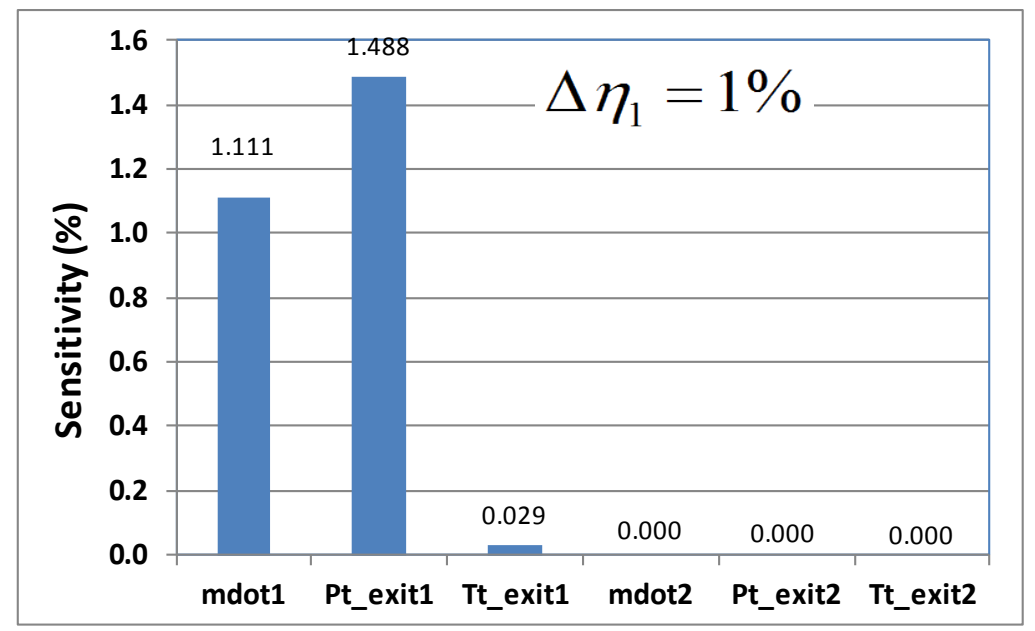

(a) When $\eta_{1}$ is varied by $1 \%$.

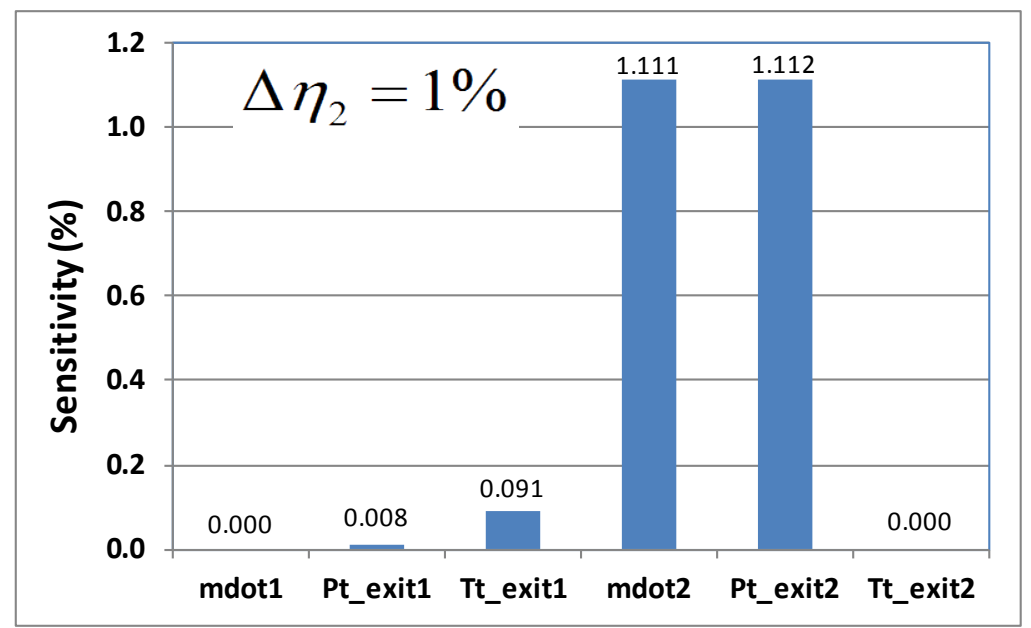

(b) When $\eta_{2}$ is varied by $1 \%$.

Fig. 6 Sensitivity of engine parameters with respect to changes in recovery at fan faces. 
Sensitivities of engine parameters are calculated for one percent variation of the recovery at fan faces. Figure 6 shows some results of the sensitivity study. All other sensitivity terms not shown in Fig.6 are all zero. The results of the sensitivity study can be summarized as follows:

1) $\dot{m}$ and $P_{t}$ are affected significantly by the recovery of its own passage only.

2) $T_{t}$ of the central passage is affected by the recovery of the central passage, but the amount of sensitivity is negligible.

3) $P_{t}$, and $T_{t}$ of the central passage are slightly affected by recoveries of side passages because the turbine work of the core engine to drive side fans is affected by mass flow rates of the side passages, which depend on the recovery values at the side fan faces. However, the amount of sensitivity is negligible.

4) The recovery of the central passage has no effects on $\dot{m}, P_{t}$, or $T_{t}$ of side passages.

Through the sensitivity study, the number of response surface models can be reduced from nine to three; $\left(f_{m}, f_{P 1}, f_{P 2,3}\right)$, and each model is a function of only the recovery of its own passage.

$$
\begin{gathered}
\dot{m}_{1}=f_{m}\left(\eta_{1}\right), P_{t 1}=f_{P 1}\left(\eta_{1}\right), T_{t 1}=\text { const }_{1} \\
\dot{m}_{2}=f_{m}\left(\eta_{2}\right), P_{t 2}=f_{P 2,3}\left(\eta_{2}\right), T_{t 2}=\text { const }_{2,3} \\
\dot{m}_{3}=f_{m}\left(\eta_{3}\right), P_{t 3}=f_{P 2,3}\left(\eta_{3}\right), T_{t 3}=\text { const }_{2,3}
\end{gathered}
$$

Data points for response surface models can be generated by conducting off-design simulation of the NPSS engine model for different inlet recovery values. In Fig.7, the resulting engine parameters of interest for airframe-engine integration perspective are plotted, and least squares curve fitting is applied to obtain algebraic response surface models.
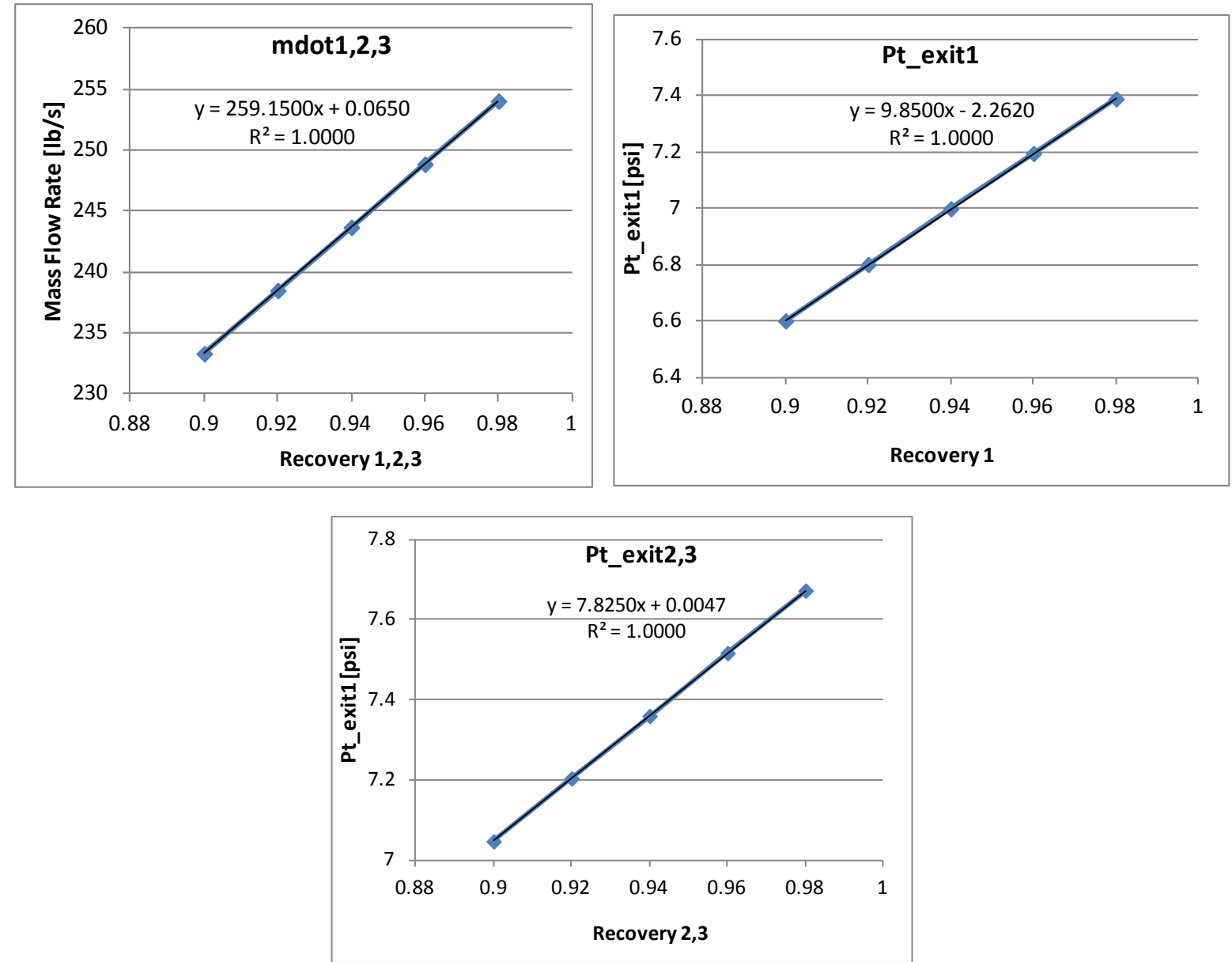

Fig. 7 Response surfaces for the NPSS engine model at the maximum power condition with Mach $0.8, h=35 \mathrm{k} f t$. 


\section{Sectional area distribution in the S-duct}

The one-dimensional section area distribution inside the S-duct has a big impact on the performance of an offset inlet. Three sections of the N2B offset inlet shown in Fig.8 correspond to (1) the inlet throat section, (2) the position just after the vertical splitter dividing core and side passages, and (3) the engine fan face. The section area increases in the first half of the inlet duct from section (1) to section (2) and decreases in the second half of the duct from section (2) to section (3), a trend following an inlet design concept in Ref. [10] to reduce flow separation in the S duct. In Ref. [10], also discussed is to apply pre-compression (in front of the inlet) so as to reduce required diffusion amount inside the inlet.

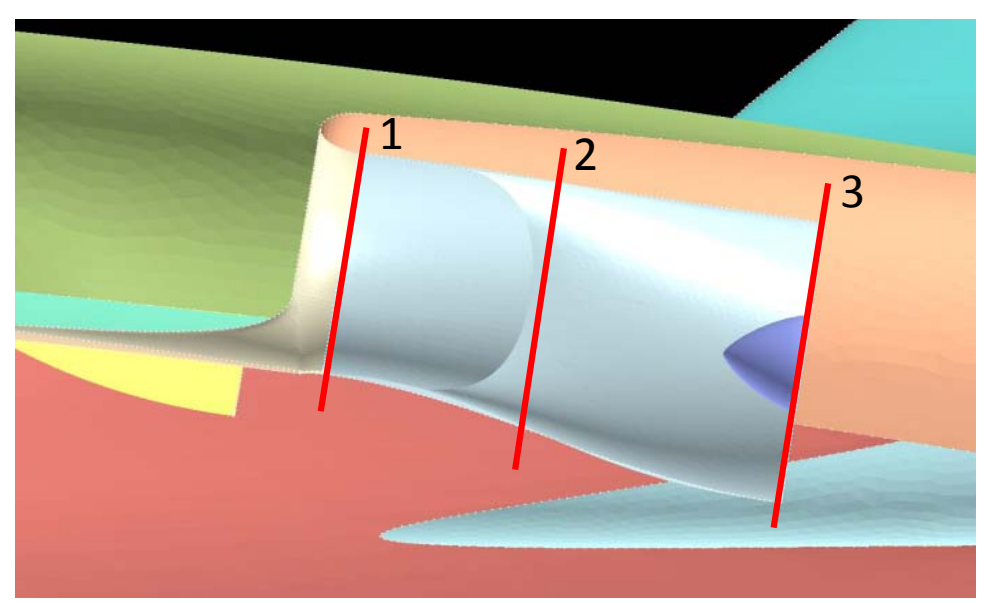

(a) Section geometry of center passage

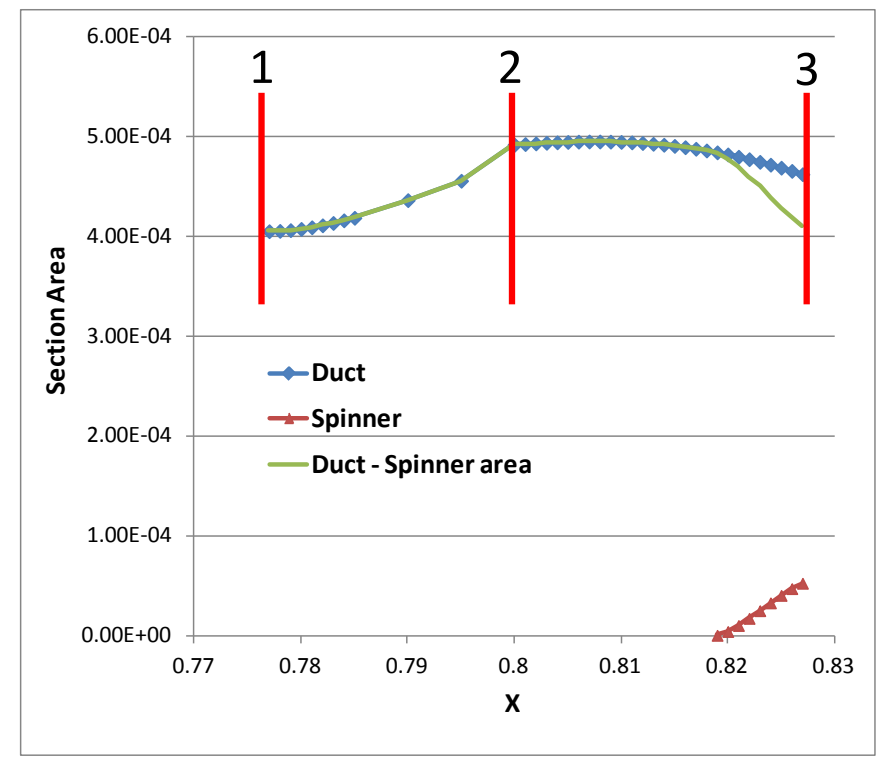

(b) Area distribution of duct and spinner

Fig.8 Section area distribution inside the S-duct.

In the original CAD geometry of the N2B aircraft, the spinner at the fan hub was not included. The spinner geometry was added into the model in the present study to be consistent with the area and average Mach number at the fan face determined through the NPSS engine thermodynamic cycle design. As evident in Fig. 8 (b), the final area distribution after subtracting spinner area from the duct area has nearly the same magnitude of areas at sections 1 and 3 , which means the net diffusion made through the duct is very little. In the design of section area distribution of an S-duct, the fan hub or spinner area needs to be considered for a better diffusion performance of the inlet duct. 


\section{Methodologies for Flow Analysis}

\section{A. Flow Solver}

GO-flow [9], a finite-volume unstructured-grid Navier-Stokes solver, is used in the current flow simulations. The compressible Reynolds-averaged Navier-Stokes (RANS) equations are discretized by the cell-vertex finite volume method. Control volumes are non-overlapping dual cells constructed around each node. Each edge connecting two nodes is associated with an area vector of the control surface, at which flow fluxes are computed. For a second order accuracy, a linear reconstruction of the primitive gas dynamic variables inside the control volume is used in conjunction with a limiter. The inviscid flux is computed using approximate Riemann solvers. Turbulence effects are considered by using Mentor's two equations Shear Stress Transport (SST) model [11, 12]. For the time integration, the Lower-Upper Symmetric Gauss Seidel (LU-SGS) implicit method is adopted [13]. Parallel processing is made by domain decomposition of the computational mesh and Message-Passing Interface (MPI). A validation study of the flow solver on a BLI offset inlet configuration is presented in Appendix.

\section{B. Grid Generation}

A triangular surface mesh is generated directly on Stereolithography (STL) data, which can be generated from a CAD model. Generation of a hybrid volume mesh is made by using advancing front/layer methods adopted in MEGG3D [14, 15]. Prism layers are generated near viscous walls, tetrahedral cells in the remaining computational domain and pyramid cells in between when necessary. Figure 9 (a) displays a surface mesh for the symmetric N2B configuration. Figure 9 (b) shows a top view of duct system splitting into three branches. The surface mesh near nozzles is shown in Fig.9 (c). As mentioned earlier for Fig.2 (b), the N2B aircraft has variable area thrust vectoring nozzles, which inevitably contain moving parts contacting each other or having very small gaps in between. The complex geometry of movable devices was simplified into clean exhaust nozzles as shown in Fig.9(c). If the thrust vectoring function needs to be simulated, the simplified surface geometry can be deformed for that purpose.

The number of computational mesh points for the N2B configuration is about 13.3 million, and first nodes off the viscous walls are clustered to the wall so that the maximum $y+$ value is less than 2 .

\section{Boundary Conditions}

Freestream conditions are for a cruise flight at Mach number of 0.8 and altitude of 35,000 ft. Freestream boundary conditions for turbulence valriables are set as $k_{\infty} / u_{\infty}^{2}=10^{-6}, \omega_{\infty} L / u_{\infty}=5$ following recommendations given in Ref.[12].

For the engine fan face boundary conditions, we extrapolate the density and velocity components from inside of computational domain and impose a static back pressure to match the target mass flow rate. For the engine nozzle exhaust planes, the total pressure and total temperature are set and a static pressure is taken from downstream in the computational domain for subsonic inflow boundary conditions.

\section{Flow Analysis Results for N2B}

The integrated airframe-nacelle configuration shows complex flow features.As shown in Fig.10, flow over the upper surface accelerates around the outer surface of cowl lip higher than Mach 1.15, which may cause shock induced boundary layer separation. Figure 11 shows flows are separated inside of S-ducts and nacelle upper surfaces. 


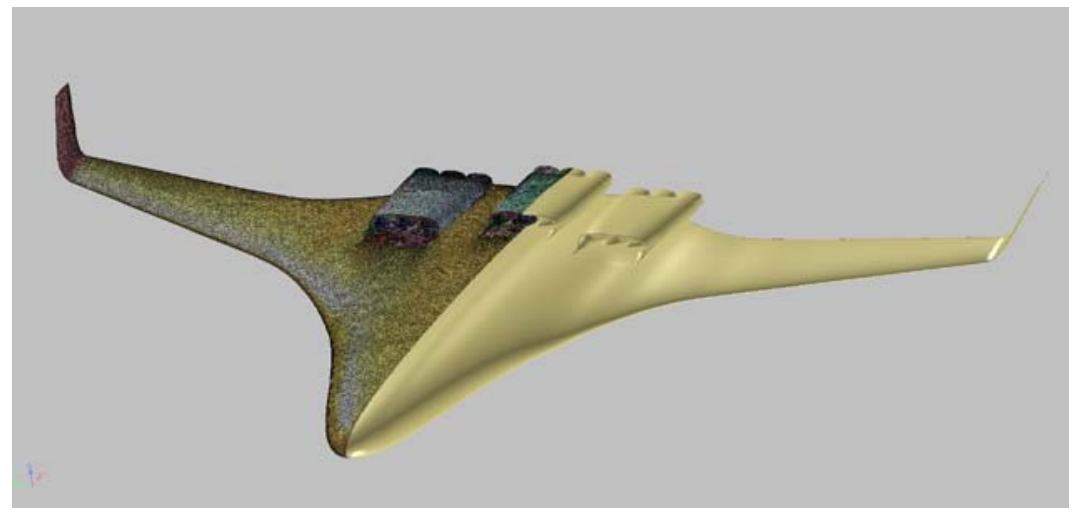

(a) Overall Surface mesh for symmetric half model.

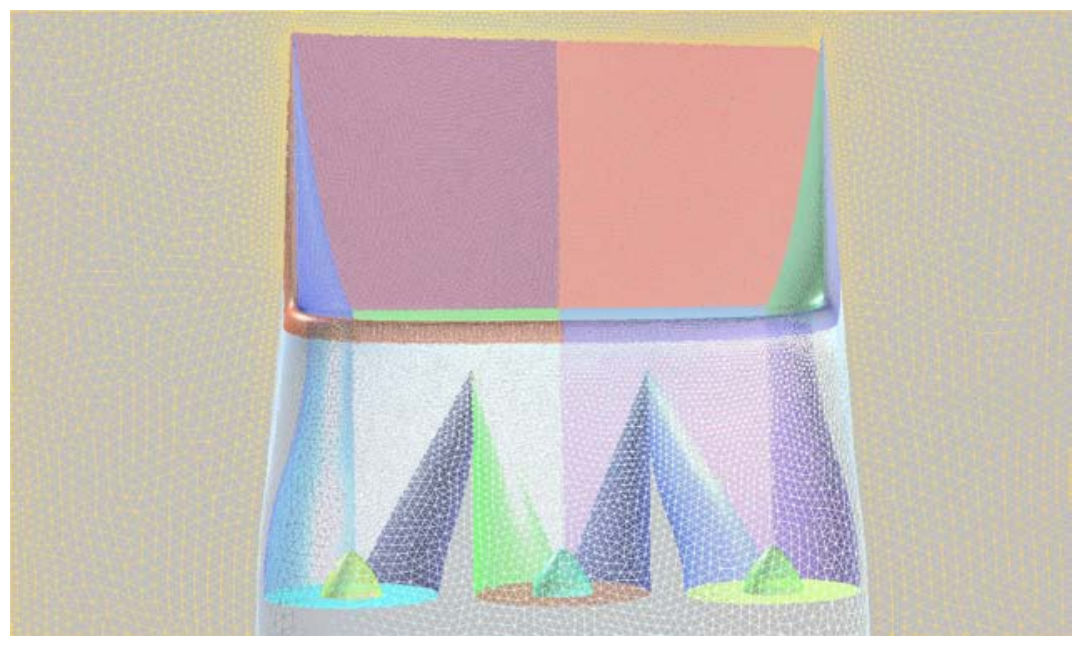

(b) Top view of S-duct and spinners at fan faces.

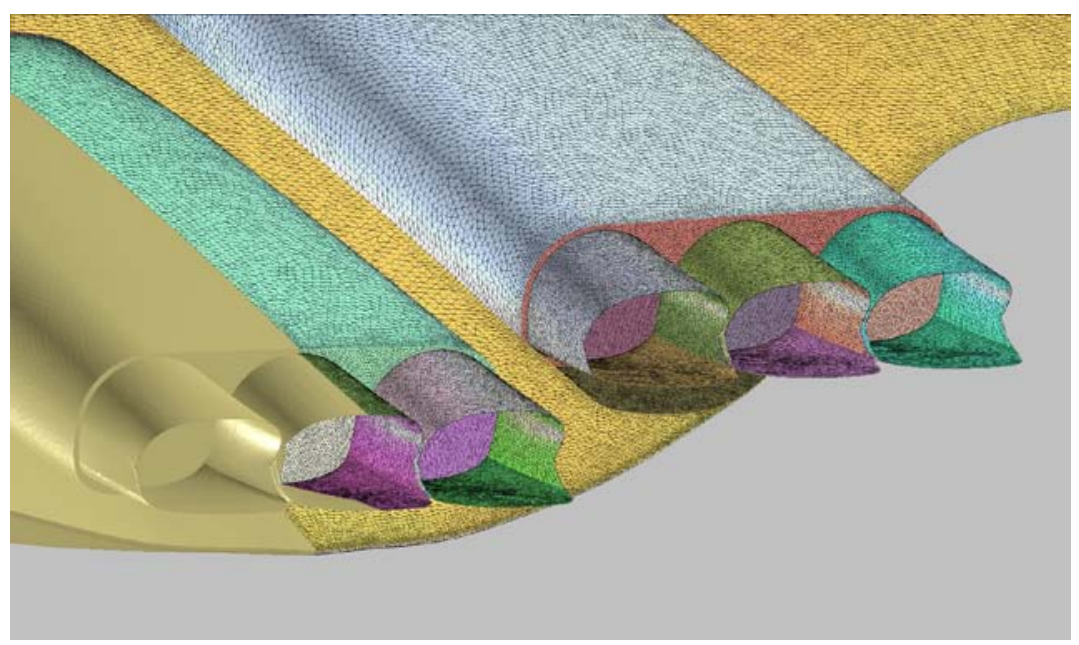

(c) Near the nozzles.

Fig. 9 Surface mesh for the N2B configuration. 

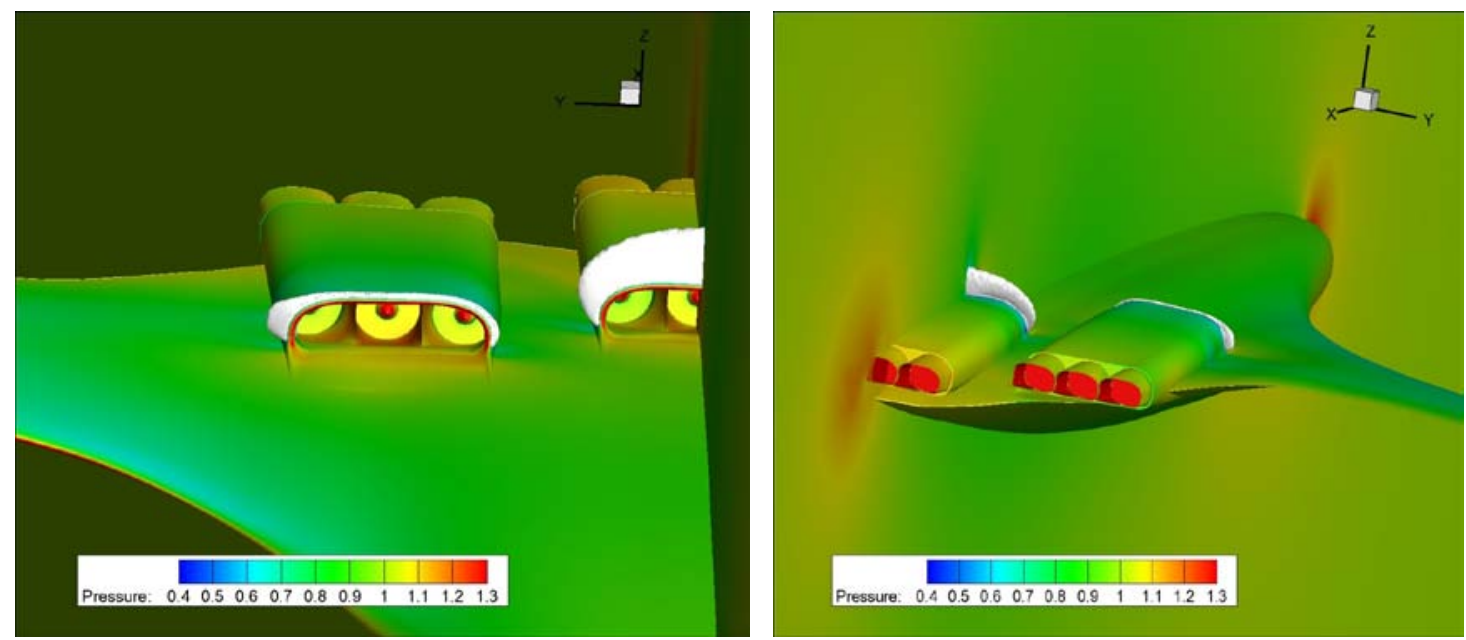

Fig. 10. Supersonic envelop with $M>1.15$.
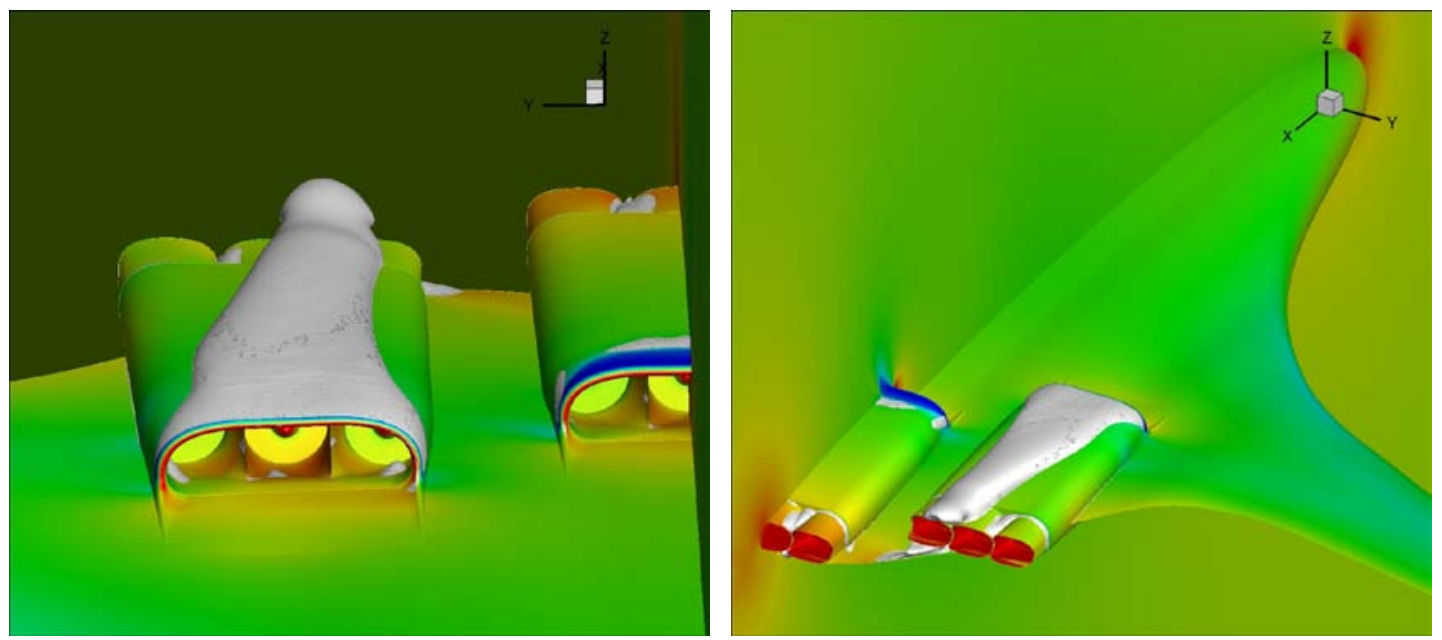

(a) Iso-contours with u velocity $<-0.01$
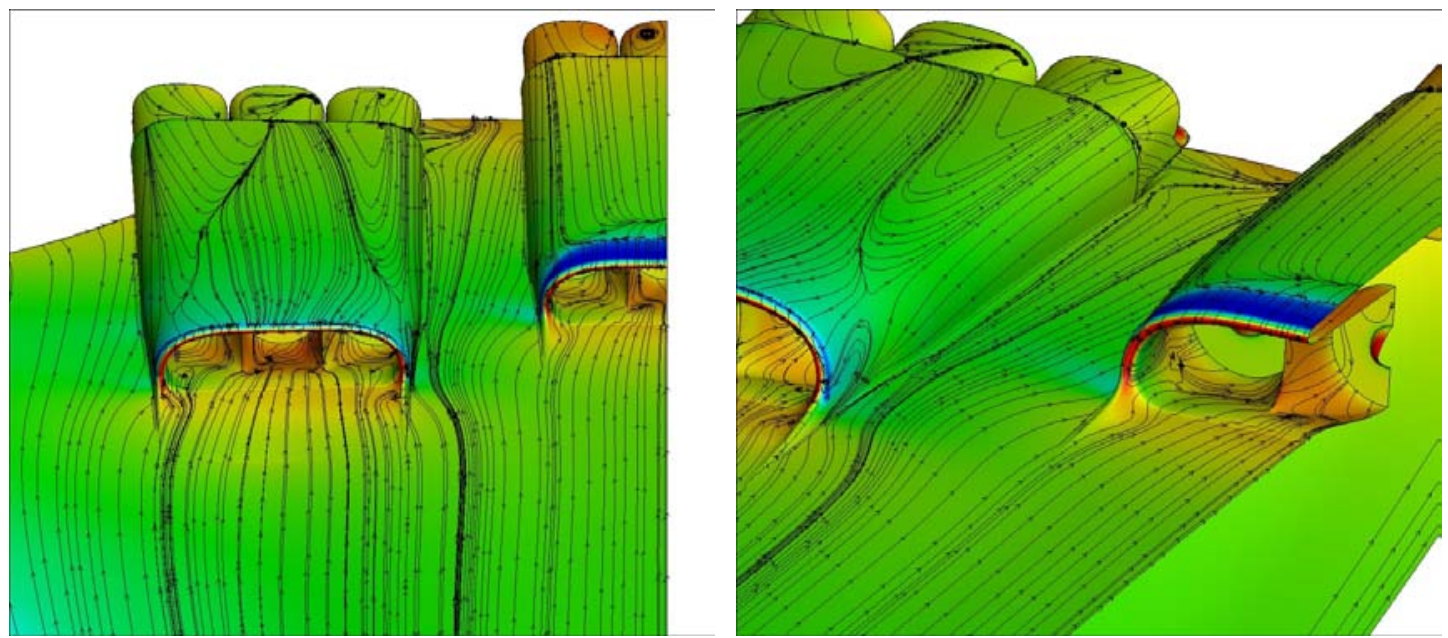

(b) Oil flows on viscous walls.

Fig. 11. Separation patterns 


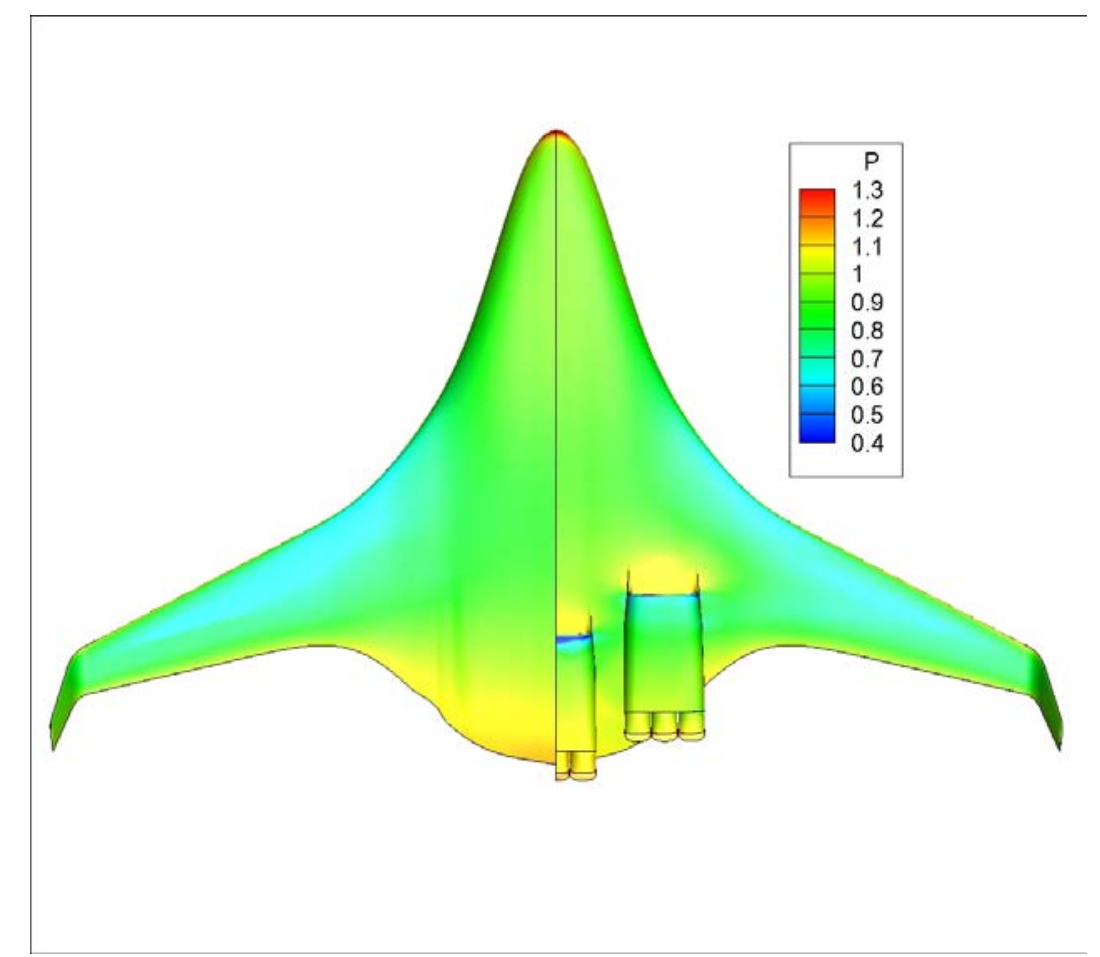

Fig. 12. Comparison of upper surface pressure contours of N2B and clean wing HWB. (left: clean wing, right: N2B).

The upper surface pressure contours fo the N2B and clean wing HWB which does not have any engine installed are compared in Fig.12. The installation of embedded engine nacelles on the upper surface causes higher pressure in front of the inlets due to the pre-compression, which is expected to cause a lift deficit for N2B.

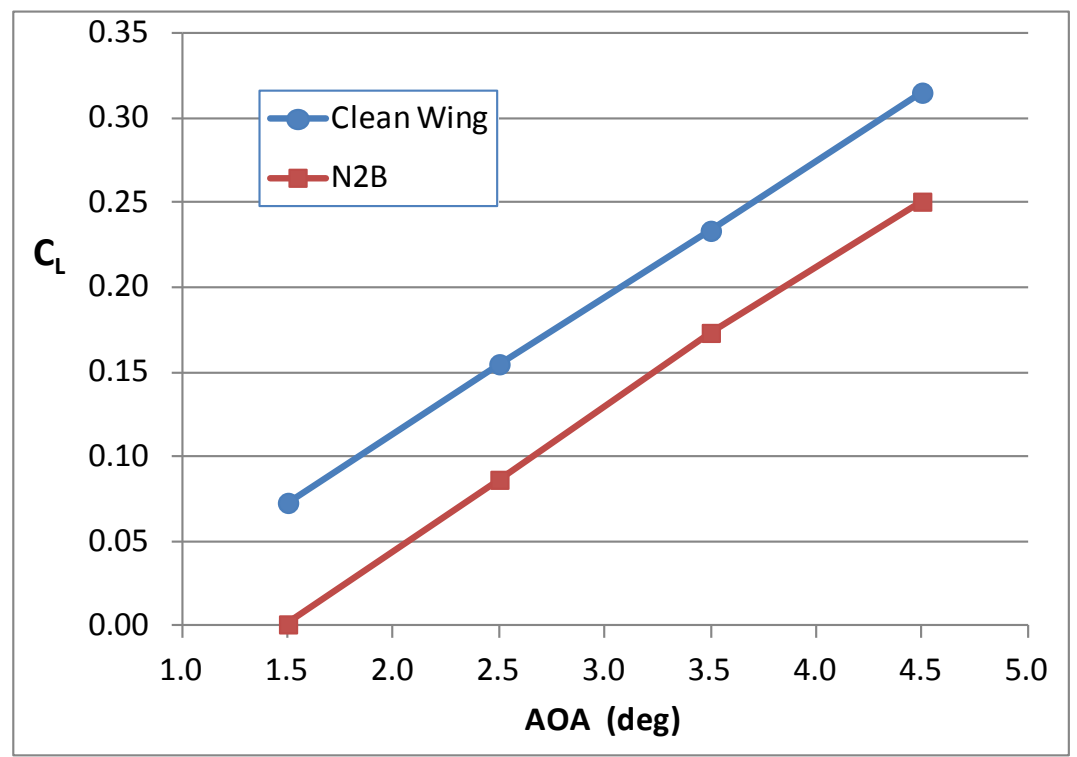

Fig. 13 Comparison of lift coefficients between clean wing and N2B. 

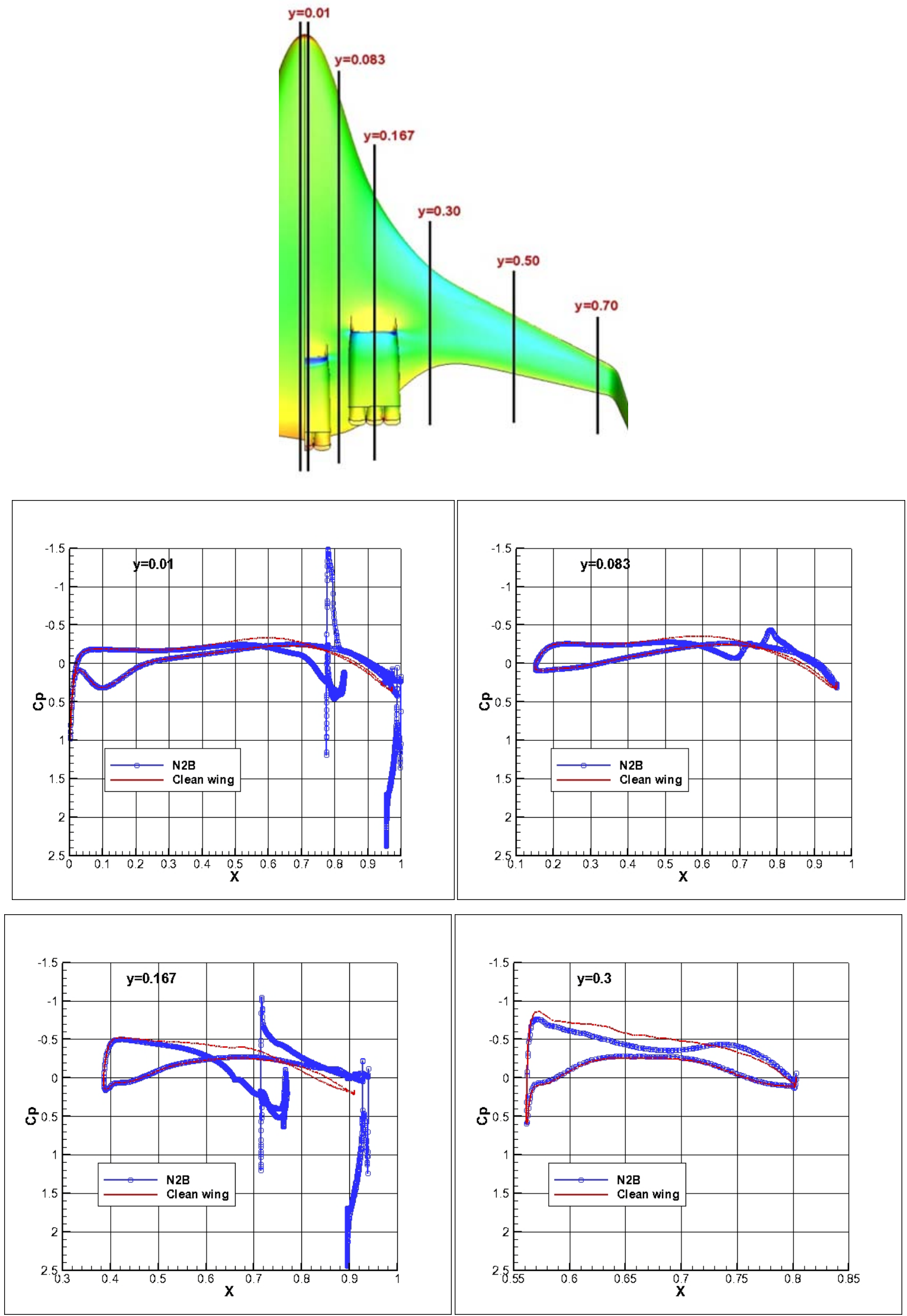

Fig. 14 Comparison of section pressure distributions between clean wing and N2B. 

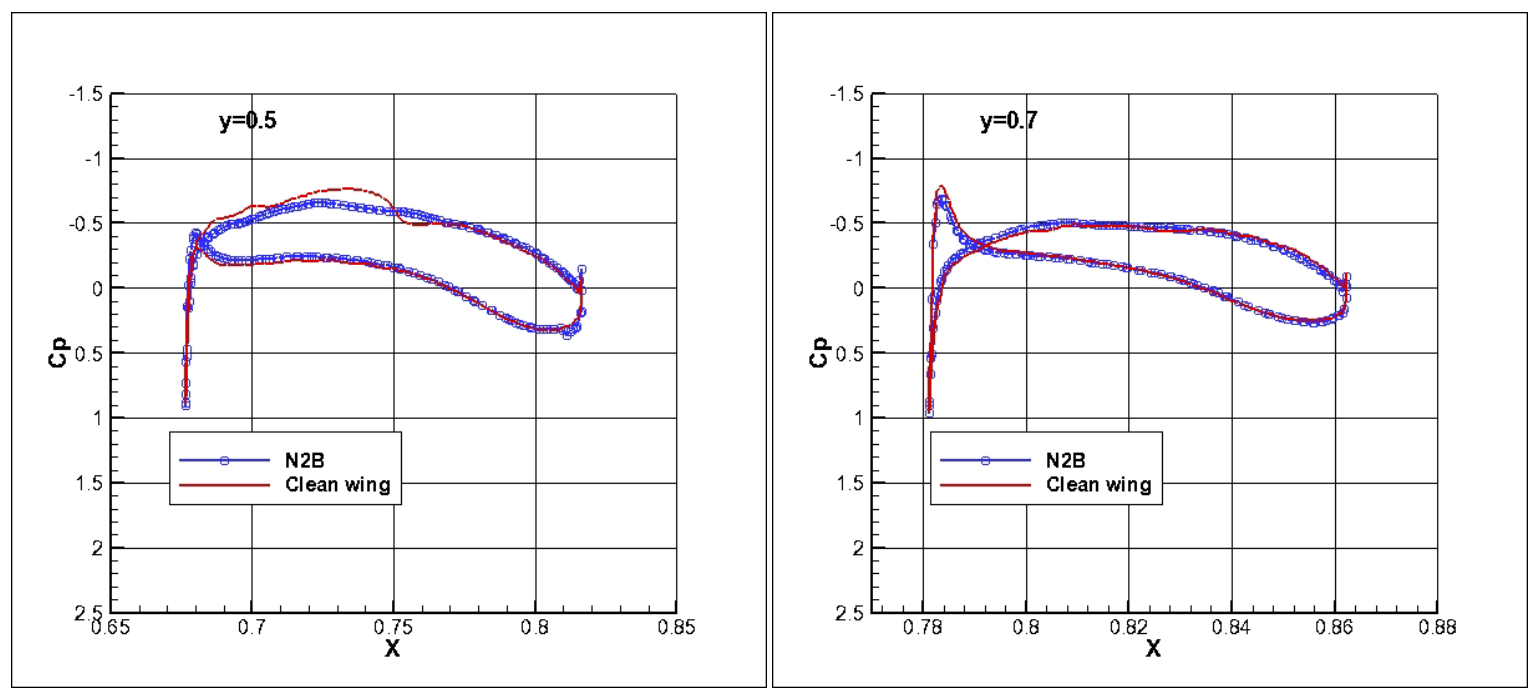

Fig. 14 Comparison of section pressure distributions between clean wing and N2B. (cont'd)
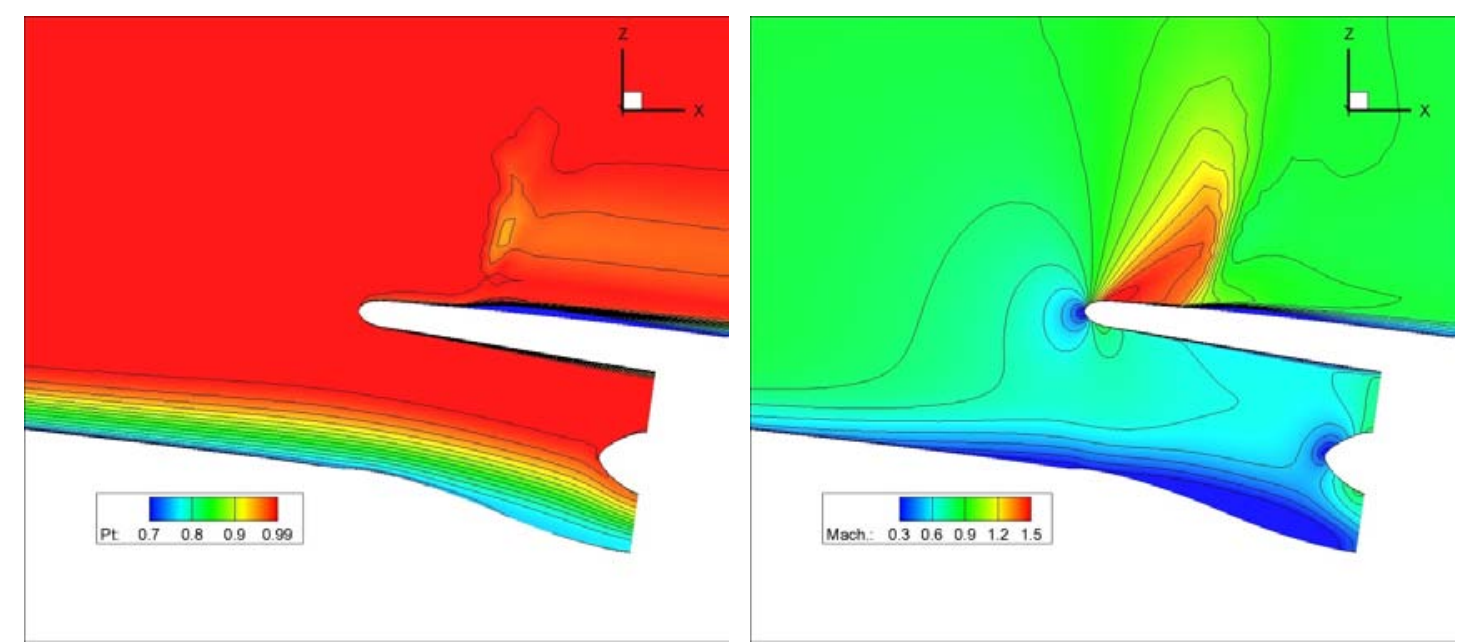

(a) Total pressure and Mach contours at symmetric plane.
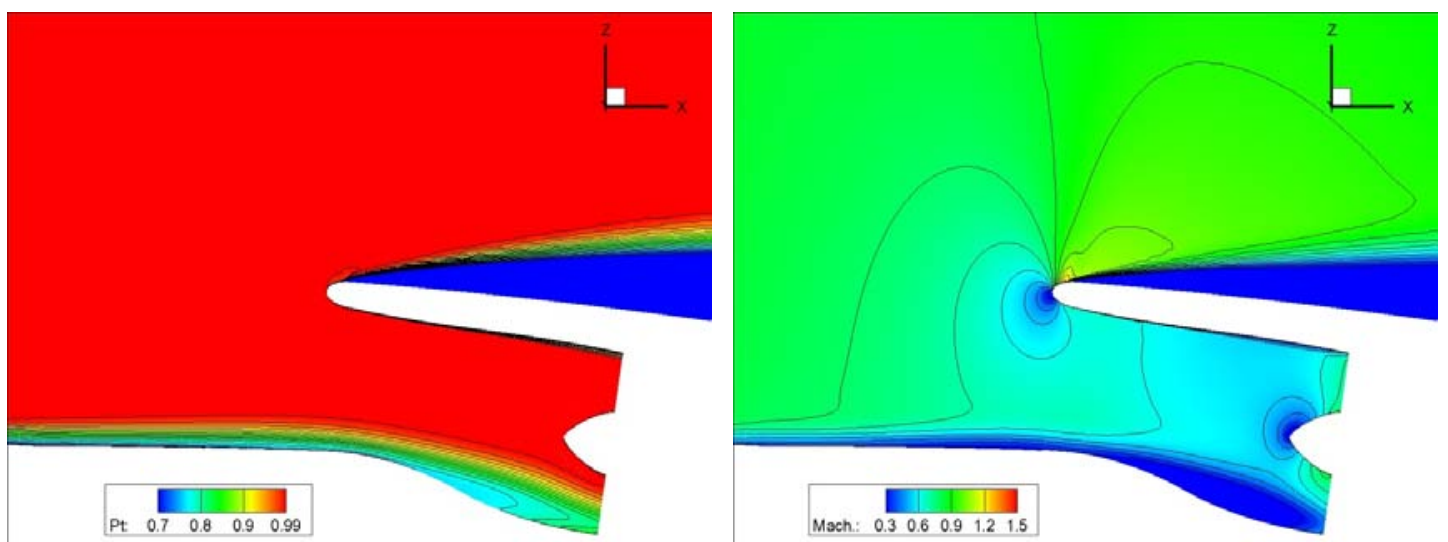

(b) Total pressure and Mach contours at center plane of outer inlet.

Fig. 15. Total pressure contours at inlet center sections. 
The boundary layer ingestion can be visualized by total pressure contours at the center section of each inlet, as shown in Fig.15. The center inlet has a thicker boundary layer ingested into the S-duct than the side inlet, because of the longer distance form the airframe leading edge to the inlet entrance. Mach contours in Fig.15 also show flow separation patterns on the upper surface of the nacelle. It is noted that there is a big difference in surface slopes in front of the offset inlet at the symmetric plane and the center plane of the outer inlet. At the symmetry plane, the upper surface before entering the inlet is well aligned with the outer surface of the nacelle. On the other hand, at the center plane of outer inlet, the nacelle cowl angle has a quite large relative incidence angle to the incoming flow along the upoper surface. This relative angle of attack of the cowl lip is causing the leading edge separation on the upper surface of the nacelle of the outer inlet. This is due to the fact that the $\mathrm{x} / \mathrm{c}$ (relative longitudinal location to the section airfoil chord length) of the inlet entrance is abount $77 \%$ for the symmetric plane and $61 \%$ for the center plane of the outer inlet. The difference of local x/c means a difference in local slopes of the section airfoil surfaces. Since a HWB aircraft tends to have a large variation of the section chord length, cowl lip angles of embedded engine nacelles should be designed to align with local inflow directions.
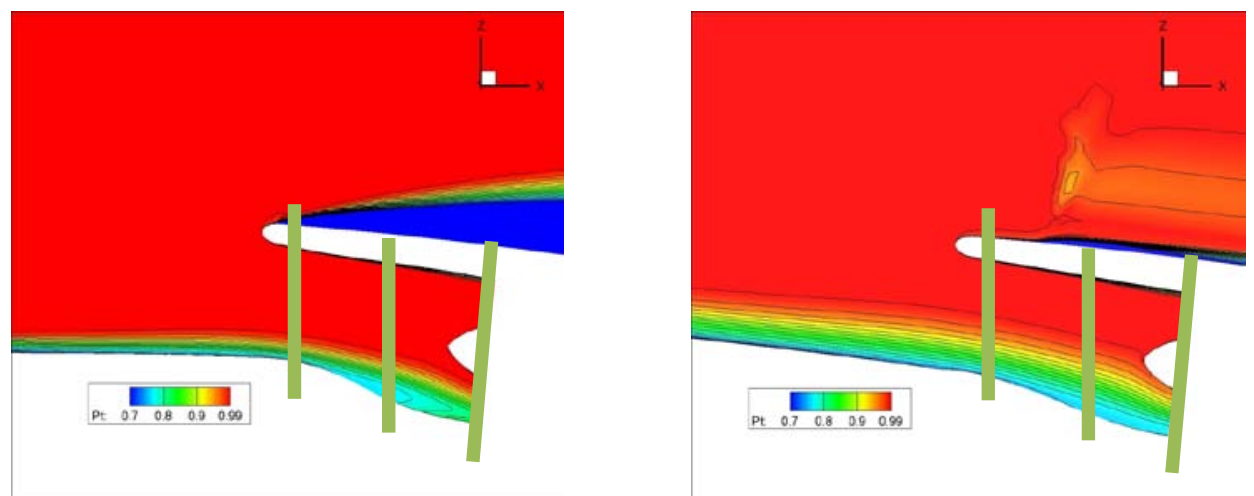

(a) Location of streamwise section cuts

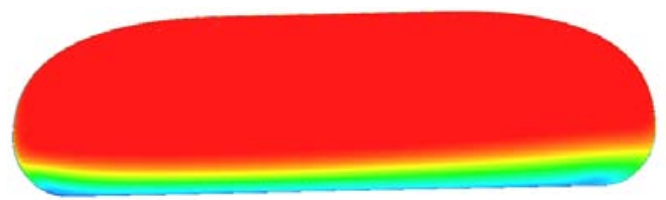

$X=0.718$
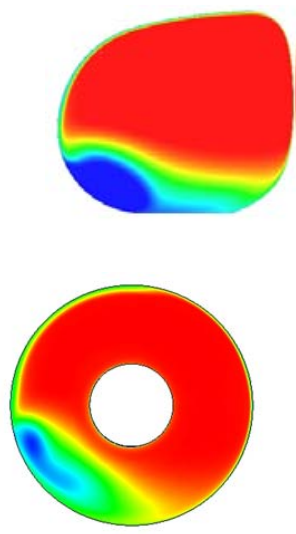

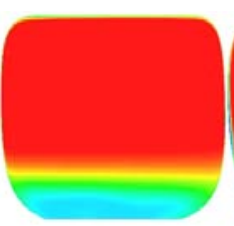

$X=0.74$

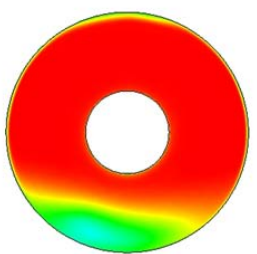

AIP
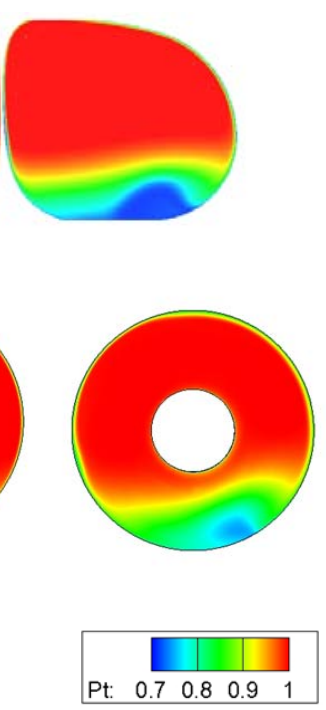
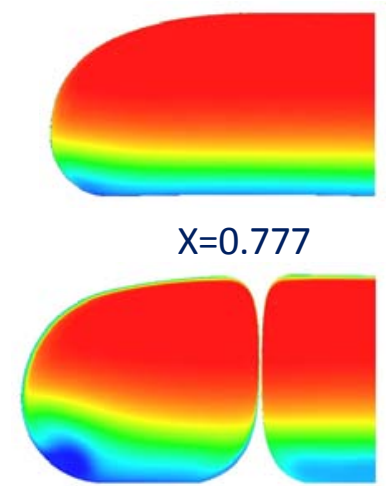

$X=0.80$

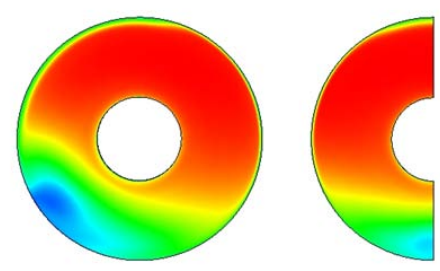

AIP

(b) Total pressure normalized by freestream total pressure

Fig.16 Total pressure contours inside inlets. 
Total pressure contours in the inlets long the streamwise coordinate $\mathrm{x}$ are shown in Fig.16. The difference in the thickness of ingested boundary layers is clearly seen. The side inlet has left-right asymmetry in the contours. To explain the asymmetry, streamlines into the engine faces are visualized in Fig.17, which shows relative side angle of the inflow to the side inlet.
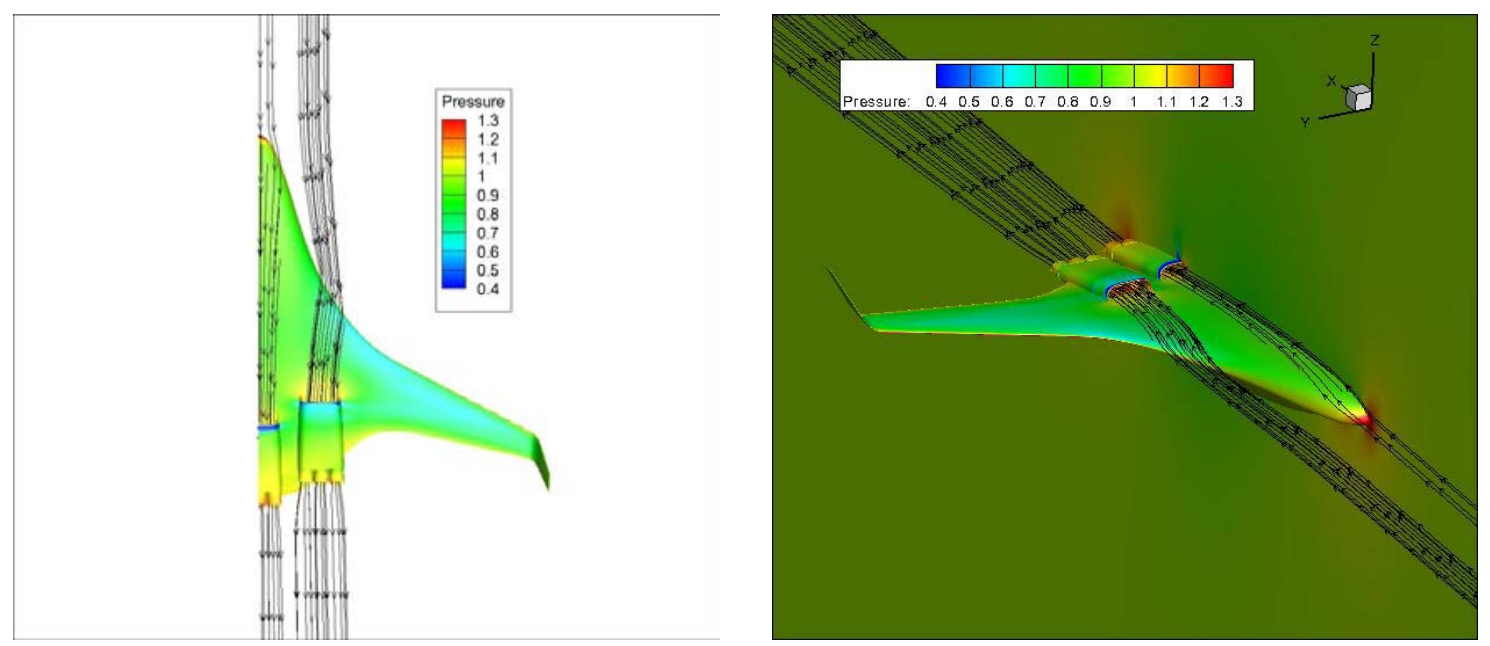

Fig. 17. Streamlines into the engine faces and out of engine nozzle exhausts.

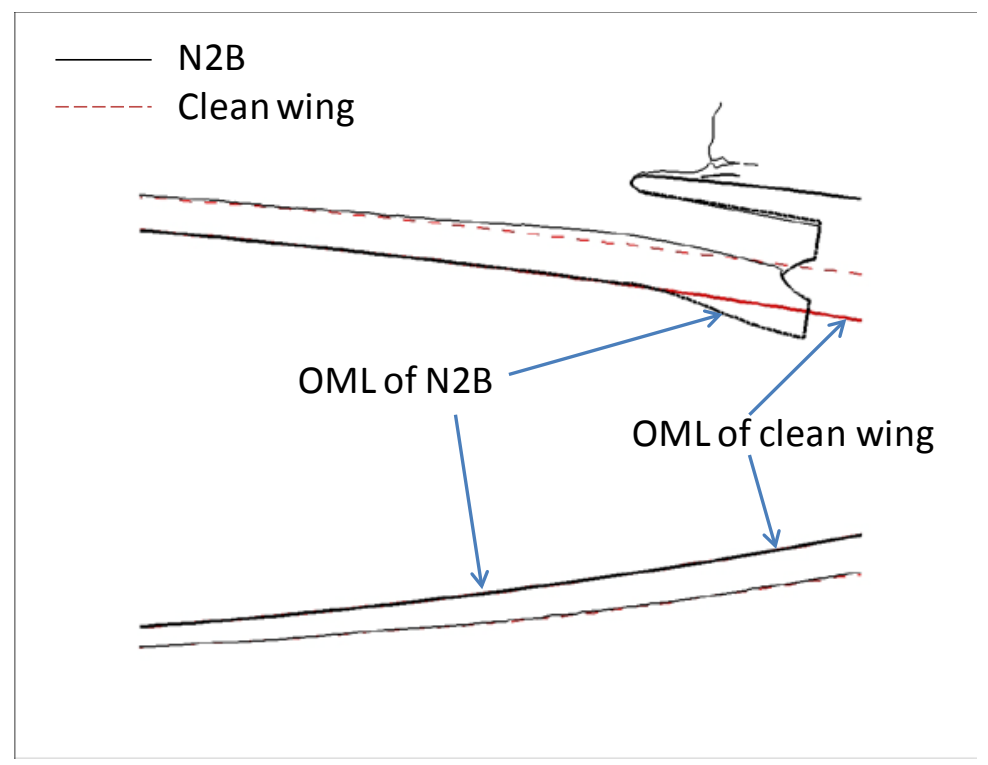

Fig. 18 Comparison of boundary layer edge lines for N2B and clean wing configurations at the symmetric plane

Boundary layer profiles obtained from CFD simulations of a clean wing configuration has been widely used for the sizing of the inlet capture area for BLI offset inlets and estimation of pressure recovery at fan faces of embedded engines[16, 3] The boundary layer thickess of the N2B and clean wing configurations are compared in Fig.18. The boundary layer thickness in the figure is defined as the contour line of $99 \%$ total pressure relative to the freestream total pressure. The boundary layer thickness is very similar between the two configurations on the upper and lower surfaces. However, as the flow over the upper surface of N2B approaches to the inlet, the boundary layer thicknessof N2B gets thicker than that of the clean wing because of the adverse pressure gradient due to the existence of the inlet and the pre-compression in front of the inlet.

In Fig.19, compared are recoveries of the side inlet obtained by clean wing simulation results and the present 
N2B analysis result. The recoveries estimated by Boeing [3] with clean wing analyses and used as input values to the NPSS engine models in Fig.4 are shown again in Fig.19 (a), where the bypass and core recoveries for the central passage are mass-weighted averaged for the design BPR 3.1. The recoveries by the clean wing results and present N2B analysis results are in excellent agreement with differences less than $0.3 \%$. Clean wing results for recoveries of the center inlet are not available. For the present N2B simulations, the recoveries for the center inlet are 0.94153, 0.95842 and 0.94153 for left, center and right passages, respectively, which are about a couple of percents lower than the side engine recoveries in Fig.19 due to the thicker boundary layer for the center engine inlet.

All the simulation results above are obtained with stationary spinner at the hub of the engine fan. Actually, the spinner is rotating at the same speed with the fan. The effects of spinning on the flow field inside the inlet is checked here by conducting the flow simulation with corresponding wall velocity boundary conditions on the spinner wall. Total pressure contours at fan faces are compared without and with rotation of the spinners in Fig. 20. As can be noted, the effect of spinning on the flow is negligible except for the spinner boundary layer.

In Fig.21, Mach contours at the symmetric plane are shown around the nozzle flow, which is choked at the throat. A separation zone is seen under the nozzle with very low local Mach number.

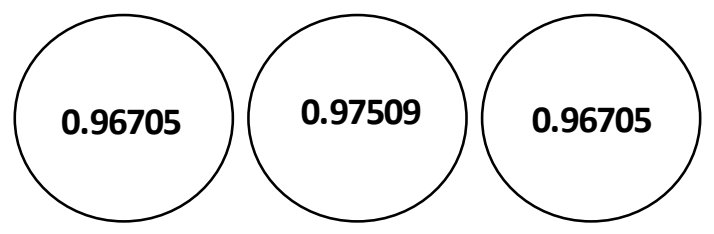

(a) Estimated recoveries by clean wing analyses results $+0.6 \%$ inlet diffuser loss

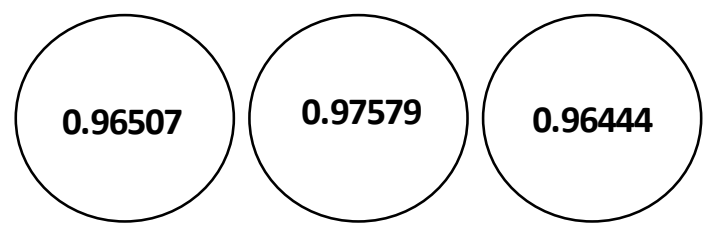

(b) The present simulation results

Fig. 19. Comparison of pressure recovery at AIP between clean wing and N2B. (front view)

Differences are $\mathbf{- 0 . 2 0 , 0 . 0 7}$ and $\mathbf{- 0 . 2 7 \%}$ for left, center and right passages, respectively.

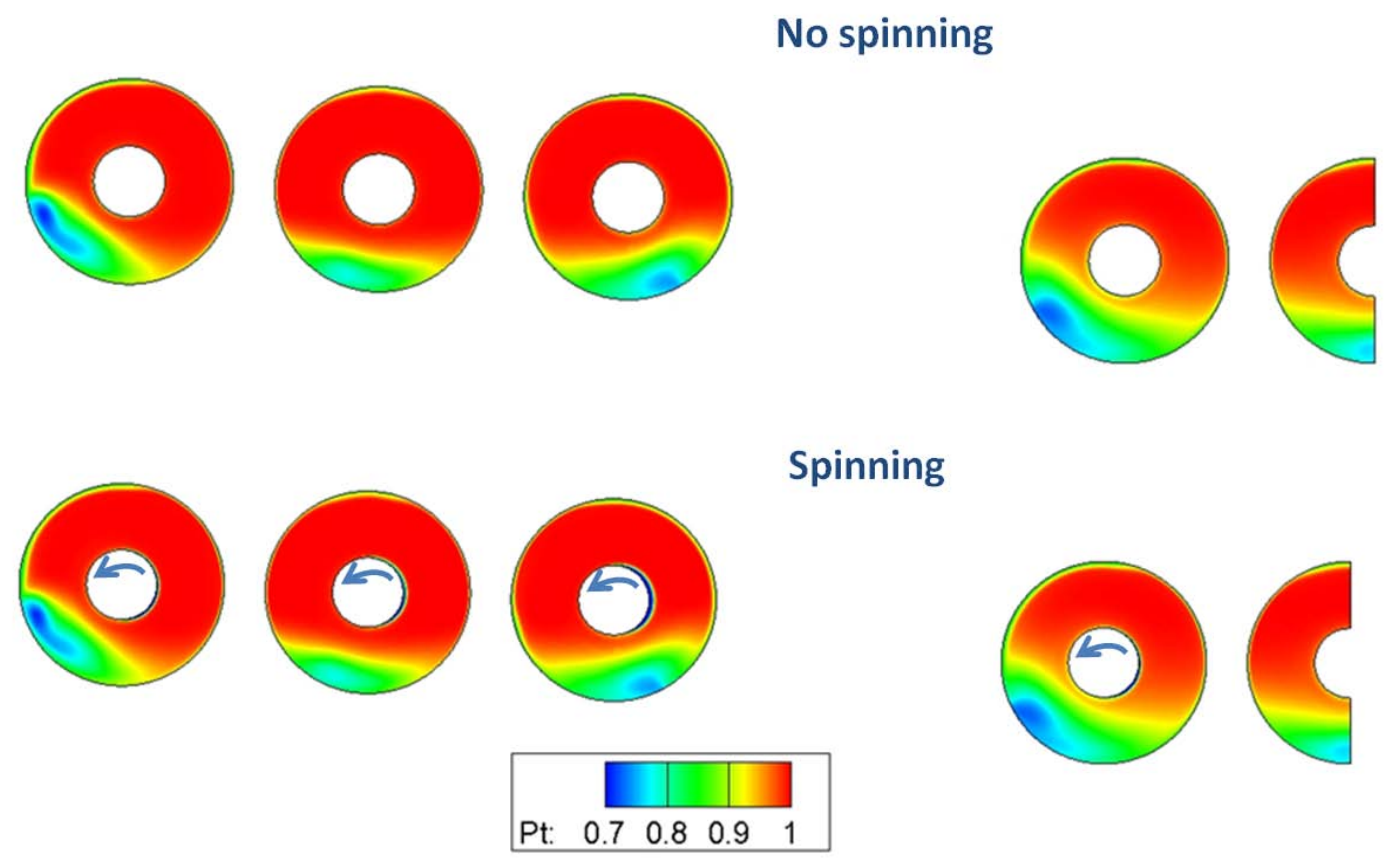

Fig. 20. Comparison of total pressure contours at fan faces with or w/o spinning hub 


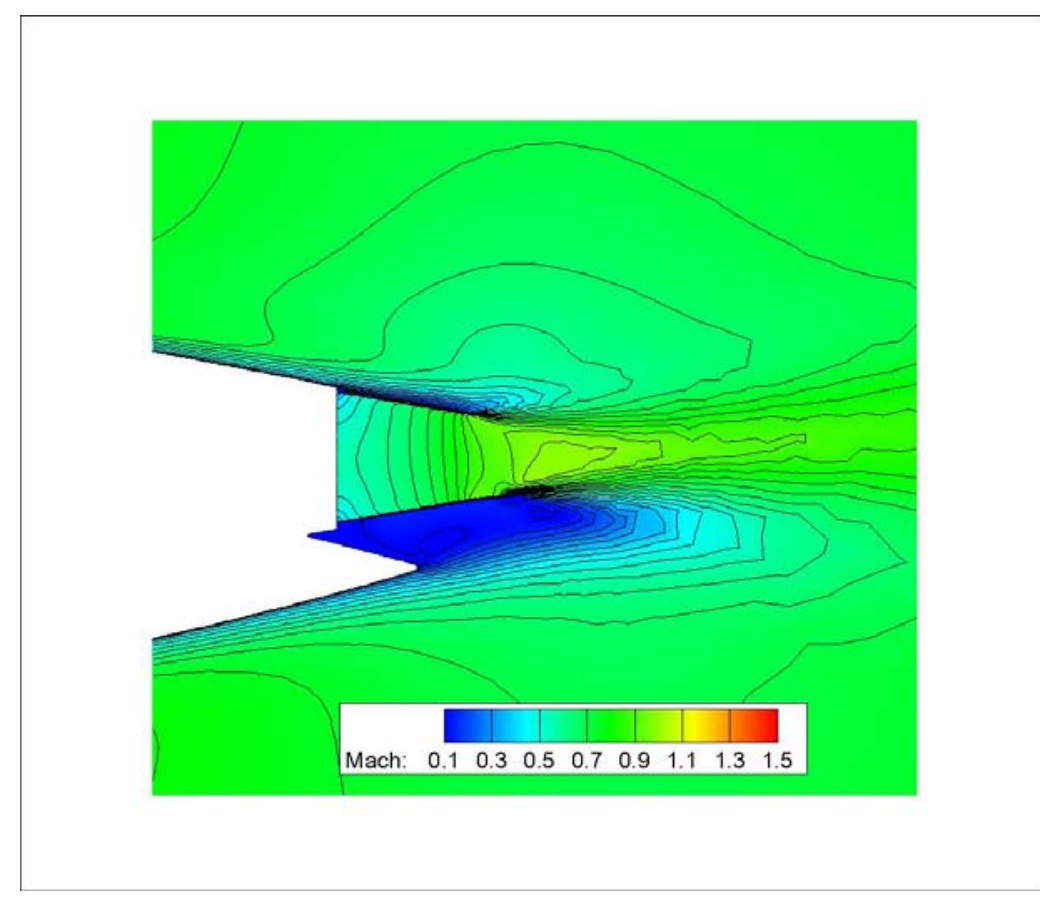

Fig. 21. Nozzle exhaust flow

\section{Concluding Remarks}

High fidelity flow simulations were conducted for the N2B Hybrid Wing Body configuration with airframe-propulsion integration effects. Thermodynamic cycle of turbofan engines proposed for the N2B aircraft were represented by the NPSS engine models. The simulation results revealed complex flow characteristics resulting from the tightly integrated airframe-propulsion system, which are very hard to estimate $a$ priori and are seen to be of considerable departure from that of a clean wing without embedded engines.

The simulation results show that the pre-compression in front of the embedded engine inlet caused a lift deficit, which is very critical in aircraft performance. Also, strong shock waves and flow separations are occurring on the nacelle upper surface. Local inflow angle effects such as side angle or incidence angle to the inlet cowl should also be considered in a detailed shape design of the airframe-propulsion system. The present flow simulation results on the hybrid wing body configuration are providing information and knowledge not only on the N2B aircraft but also on other HWB configurations with embedded engine concepts.

Future work will be focused on shape design optimization of the HWB configuration in two aspects. The first one is improving flow quality at fan faces by a redesign of BLI offset inlet including the pre-compression region in front of the inlet. Another work is reshaping airframe-nacelle integration to minimize shock waves and flow separations outside of the nacelle. These two aspects of the shape design are not independent problems, but closely coupled with each other. Therefore, application of optimal shape design is essential to achieving the above goals. 


\section{APPENDIX: Validation of the Flow Solver for Boundary Ingestion Offset Inlet Diffuser}

For validation of the flow solver on configurations including BLI offset inlets, flow simulations are conducted for a flush-mounted offset inlet shown in Fig.A1 and compared to the experimental results obtained by Owens et al.[17] at NASA Langley’s 0.3-Meter Transonic Cryogenic Tunnel, in which the inlet was flush-mounted on the tunnel sidewall.

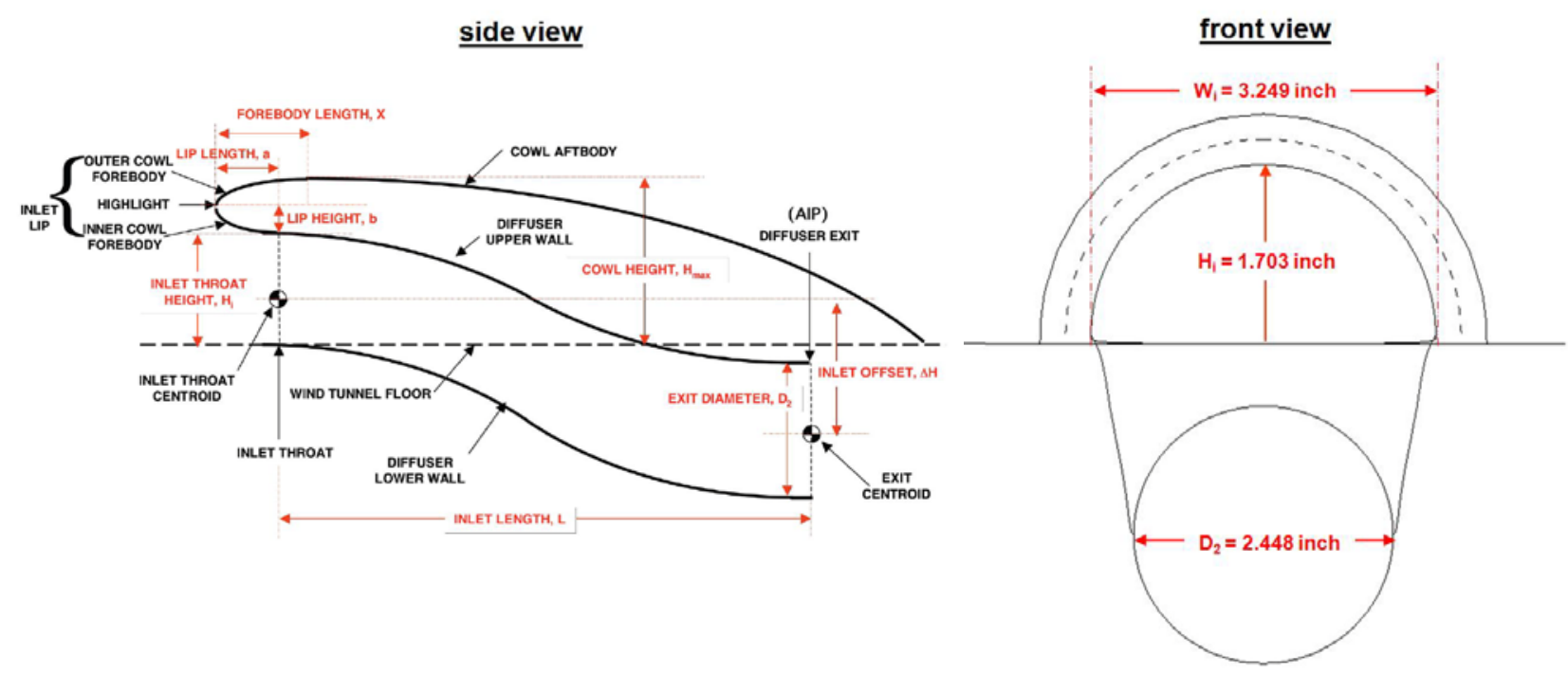

(a) Side and front views

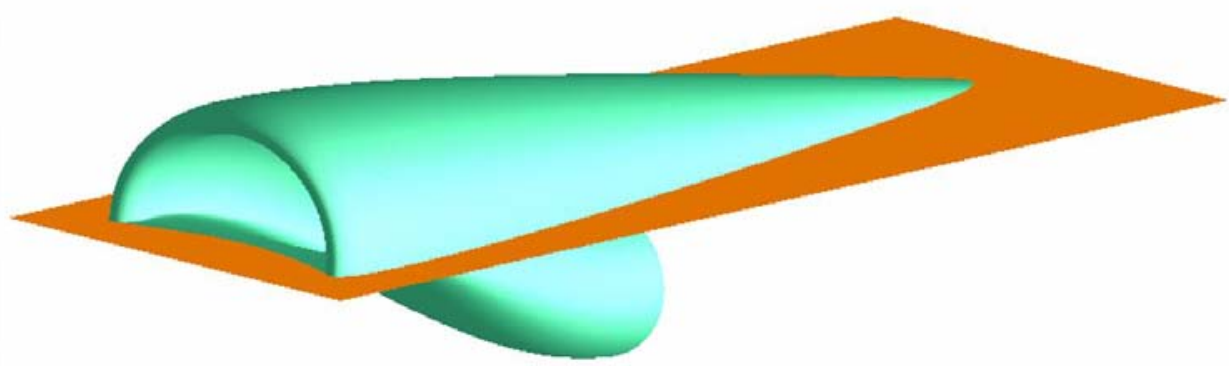

(b) CAD surface representation

Fig.A1 BLI offset inlet configuration: Inlet A model [17]

Computational mesh for the BLI offset inlet is shown in Fig.A2. Outer boundaries are composed of inflow, side, top and outlflow planes. The outer boundaries are set as freestream boundary conditions. The side, top and outflow planes respectively are 50 inches away from the inlet throat centroid. The viscous flat plate length ahead of the inlet is adjusted to match the experimental bondary layer thickness at the inlet. The total number of mesh points is about 10 million, and first nodes off the viscous wall are clustered to the wall so that maximum $y^{+}$value is less than 2 . 


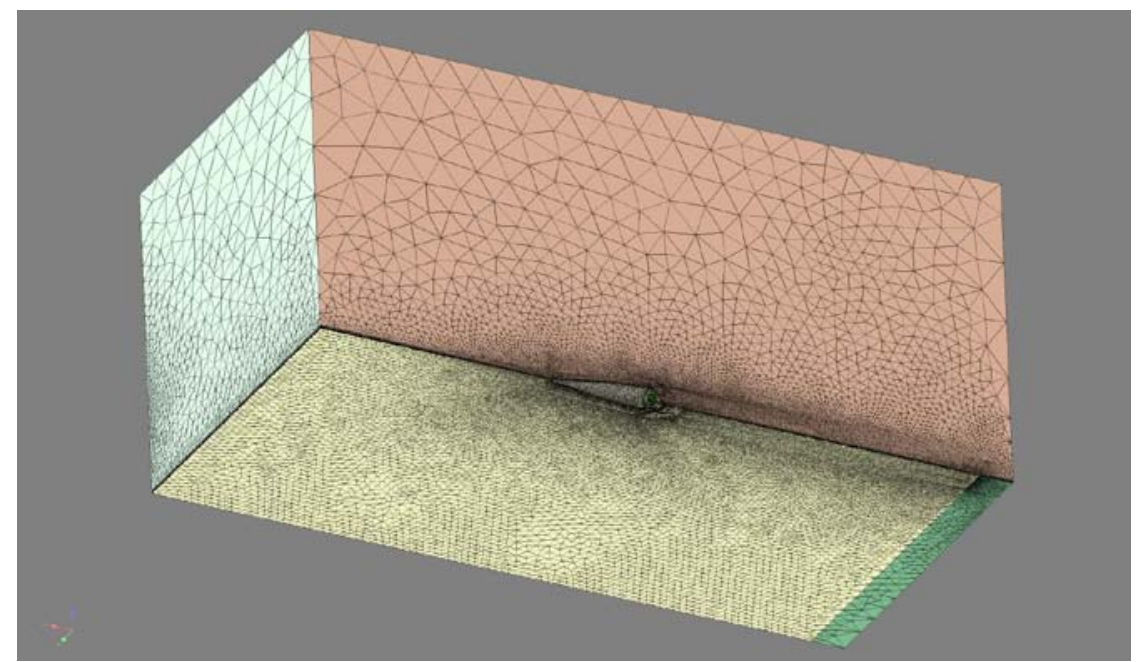

(a) Surface mesh for the computational domain

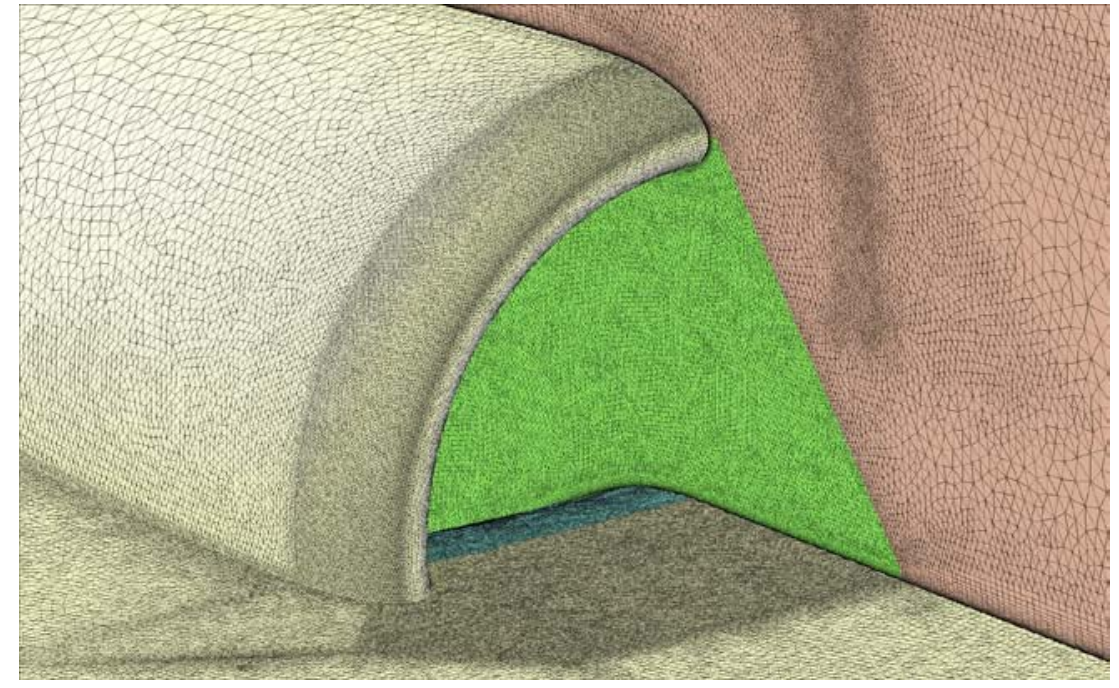

(c) Zoomed view near the inlet entrance

Fig.A2 Computational mesh

To ensure the numerical simulations are conducted at the same flow condition as the wind tunnel testing of the BLI offset inlet, several parameters need to be matched; the freestream Mach number, the Reynolds number, the boundary layer profile at the inlet, and the inlet mass flow rate. As mentioned earlier, the height of boundary layer profile is matched by adjusting the flat plate length ahead of the inlet. The inlet mass flow rate is controlled by varying a static back pressure at the AIP. The freemstream Mach number is 0.85 and the Reynolds number based on AIP diameter, $\mathrm{Re}_{\mathrm{D}}=3.8 \times 10^{6}$, which is consistent with the experimental flow conditions in Ref.[17], where the Mach number was held at a constant 0.85 upstream of the inlet. Freestream boundary conditions for turbulence valriables are set as $k_{\infty} / u_{\infty}^{2}=10^{-6}, \omega_{\infty} L / u_{\infty}=5$ following recommendations given in Ref.[12].

Because the flow field has adverse pressure gradient as the flat plate boundary layer flow approaches the inlet entrance, just matching the boundary layer height does not necessarily mean the same boundary layer is ingested into the inlet. The amount of adverse pressure gradient due to the local flow conditions in the test section of the wind tunnel would affect more the detailed shape of the boundary layer profile ahead of the inlet. Figure A3 shows velocity profiles by the present numerical simulations and experimental results at the boundary layer rake location. The computaional velocity profile in a solid line has slightly higher verlocity in the bottom part of the boundary layer, which is consistent with other CFD analysis results in Ref. [19]. Lee et al.[18] compared boundary layer velocity profiles for $\mathrm{Re}_{\mathrm{D}}=$ $2.2 \times 10^{6}$ and $3.8 \times 10^{6}$ and found the lower Reynolds number, $\mathrm{Re}_{\mathrm{D}}=2.2 \times 10^{6}$, results in a closer velocity profile to the experimental profile than the higher Reynolds number $\operatorname{Re}_{\mathrm{D}}=3.8 \times 10^{6}$. Also, $\mathrm{Re}_{\mathrm{D}}=2.2 \times 10^{6}$ results in better 
comparisons for pressure distributions with experimental data than $\mathrm{Re}_{\mathrm{D}}=3.8 \times 10^{6}$ does. Thus, it is deemed that the extent of matching the experimental boundary layer profile affects accuracy of computation of the pressure distributions inside the duct.

CFD simulations for the BLI offset inlet test case in literature often uses a lower Reynolds number than the experimental Reynolds number $\mathrm{Re}_{\mathrm{D}}=3.8 \times 10^{6}$ probably to match the boundary layer velocity profile more closely to the experimental data. (e.g. $\mathrm{Re}_{\mathrm{D}}=2.2 \times 10^{6}$ in Ref.[19]) However, the use of a lower Reynolds number also results in significantly lower total pressure recoveries at AIP. $[18,19]$ In this study, instead of changing the Reynolds number, the static back pressure of the outflow boundary plane is adjusted to match the computational and experimental velocity profiles in the boundary layer as closely as possible. In the case of back pressure adjustment, the side and top boundary surfaces are treated as inviscid walls. In Fig.A3, the graph in a dashed line shows the velocity profile obtained by the present study with adjustment of the back pressure, which is lower than the freestream pressure. Note that the outflow plane and AIP are different exit boundary planes.

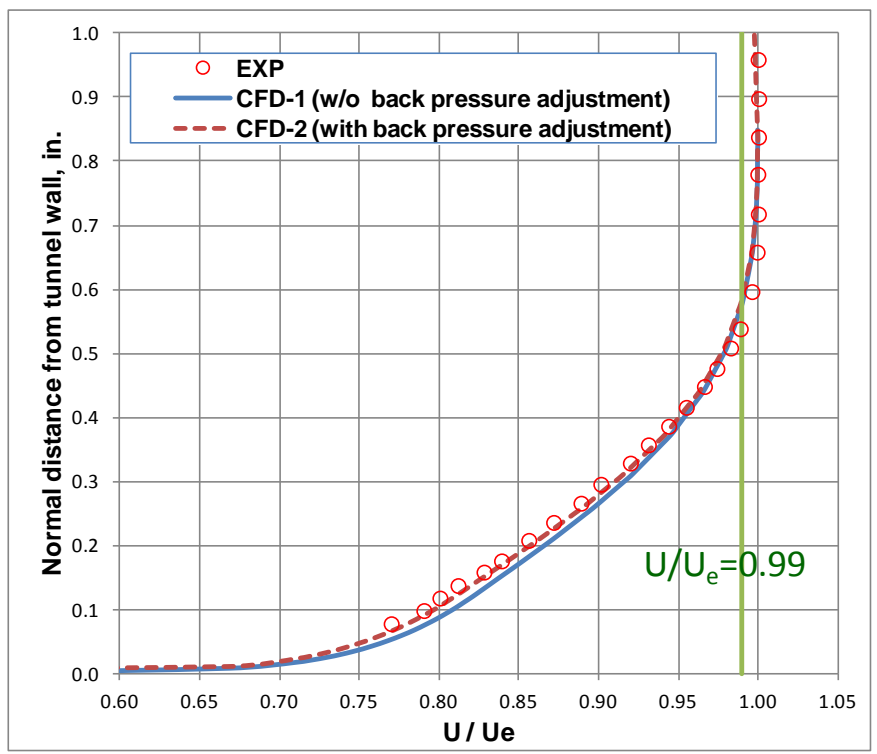

Fig.A3 Comparison of boundary layer profiles.

Exp: $M_{\infty}=0.843, \operatorname{Re}_{\mathrm{D}}=3.3 \times 10^{6}, \mathrm{CFD}: \mathrm{M}_{\infty}=0.850, \mathrm{Re}_{\mathrm{D}}=3.8 \times 10^{6}$

CFD-1: present simulation results without back pressure adjustment CFD-2: present simulation results with back pressure adjustment

Figure A4 compares inlet centerline pressures from experimental and the present CFD results. The CFD results include two sets of data without and with the back pressure adjustment for boundary layer profile matching. The pressure distribution without the back pressure correction deviates upward from the experimental data. Meanwhile the pressure with the back pressure adjustment shows a very good comparison both on upper and lower surfaces inside the inlet. 


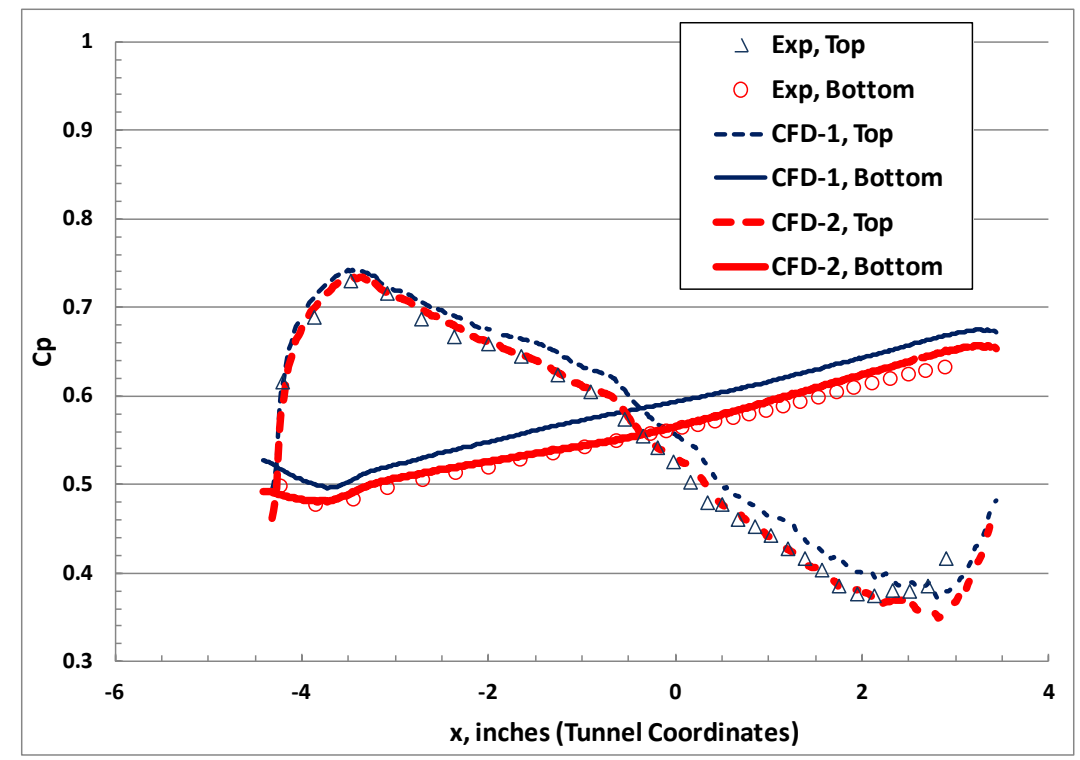

Fig.A4 Comparison of inlet centerline pressure on the top and bottom of the BLI inlet.

$M_{\infty}=0.85, R_{D}=3.8 \times 10^{6}$, Experimental data: wall correction

(See Fig. A3 for definitions of CFD-1 and CFD-2)

The inlet mass flow rate was represented by the area ratio $A_{0} / A_{c}$ where $A_{0}$ is the area in the freestream flow that corresponds to the mass flow rate fed into the inlet:

$$
\rho_{0} U_{0} A_{0}=\rho_{c} U_{c} A_{c}
$$

The inlet capture area, $\mathrm{A}_{c}$, is defined by the inlet section area at the cowl highlight. As for an indicator for flow distortion at AIP, the SAE circumferential distortion descriptor, DPCP $_{\text {avg }}$ [21] is used to compare with results of experimental and other numerical studies in the literature.

The inlet performance parameters obtained by the present flow simulations are compared with the experimental data in Table A1. The present results show good comparisons with experimental and other CFD results. Finally, contours of the local total pressure normalized by the freestream value are compared for experimental and other CFD results. The present results are calculating the location of the minimum total pressure region slightly higher than other results. Other than that, the overall trend is well simulated by the present CFD code.

Table A1 Comparison of performance parameters of the BLI inlet

(See Fig. A3 for definitions of CFD-1 and CFD-2)

\begin{tabular}{|c|c|c|c|c|}
\hline & $\mathbf{A}_{0} / \mathbf{A}_{\mathbf{c}}$ & Distortion (DPCP $\left.{ }_{\text {avg }}\right)$ & Pressure recovery & Reynolds number $\mathbf{R e}_{\mathrm{D}}$ \\
\hline Experiment [17] & 0.534 & 0.054 & 0.952 & $3.8 \times 10^{6}$ \\
\hline Present CFD-1 & 0.536 & 0.052 & 0.948 & $3.8 \times 10^{6}$ \\
\hline Present CFD-2 & 0.532 & 0.054 & 0.941 & $3.8 \times 10^{6}$ \\
\hline CFD [18] & 0.533 & 0.060 & 0.956 & $3.8 \times 10^{6}$ \\
\hline CFD [18] & 0.527 & 0.063 & 0.943 & $2.2 \times 10^{6}$ \\
\hline CFD [19] & 0.537 & 0.054 & 0.943 & $2.2 \times 10^{6}$ \\
\hline CFD [20] & N/A & 0.056 & 0.934 & $1.8 \times 10^{6}$ \\
\hline
\end{tabular}




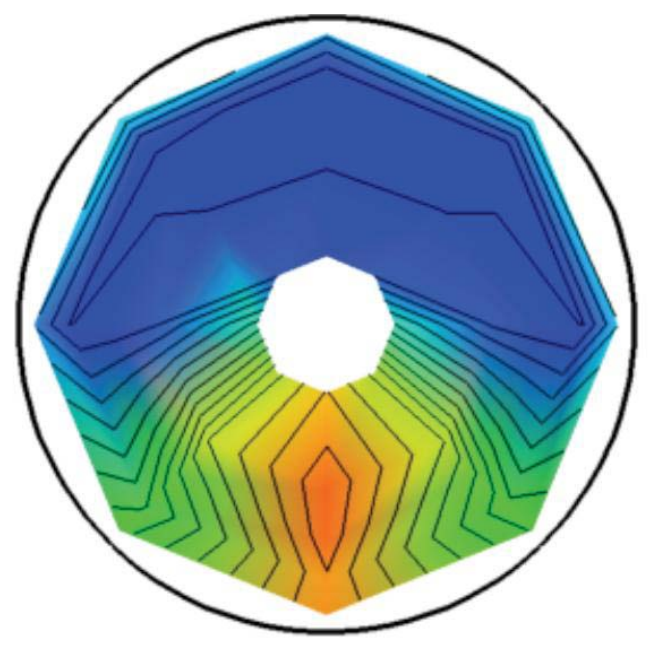

(a) Experiment $\left(\mathrm{Re}_{\mathrm{D}}=3.8 \mathrm{M}\right)[17]$

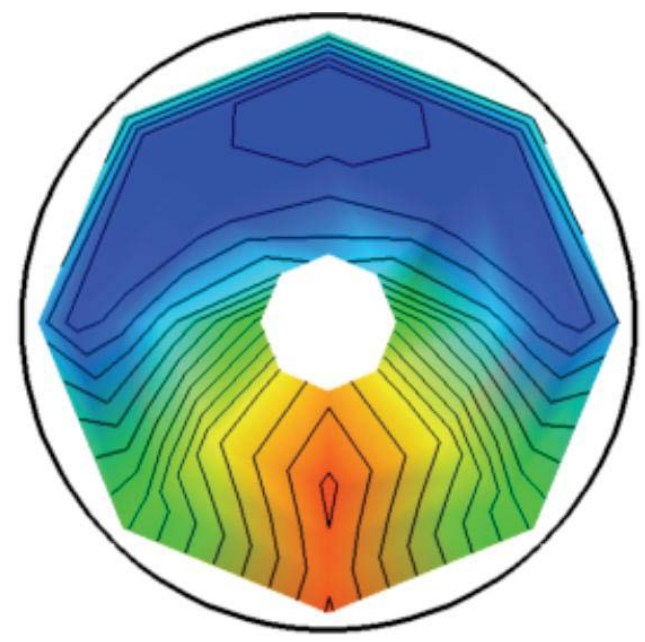

(b) $\mathrm{CFD}\left(\mathrm{Re}_{\mathrm{D}}=\mathbf{2 . 2 \mathrm { M } )}[\mathrm{19]}\right.$

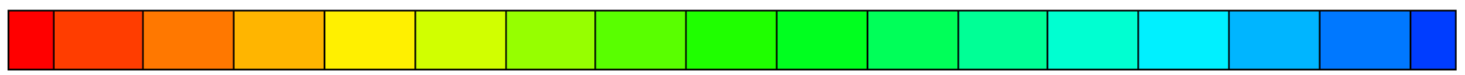

Pt: $\begin{array}{lllllllllllllllll}0.84 & 0.85 & 0.86 & 0.87 & 0.88 & 0.89 & 0.9 & 0.91 & 0.92 & 0.93 & 0.94 & 0.95 & 0.96 & 0.97 & 0.98 & 0.99\end{array}$

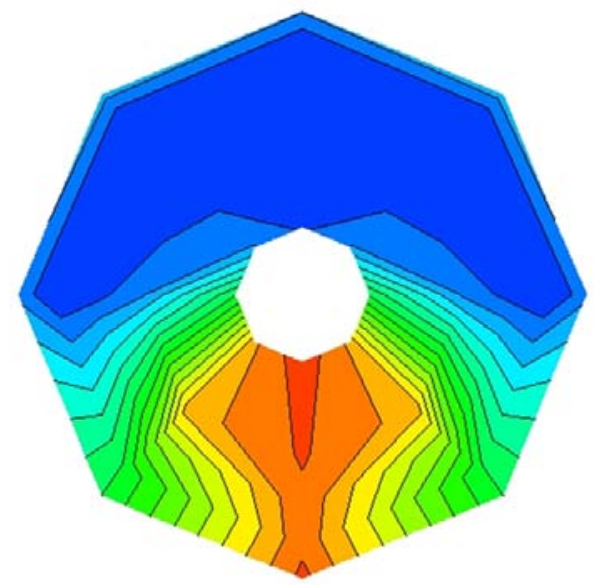

(c) Present CFD-1 $\left(\operatorname{Re}_{\mathrm{D}}=3.8 \mathrm{M}\right)$

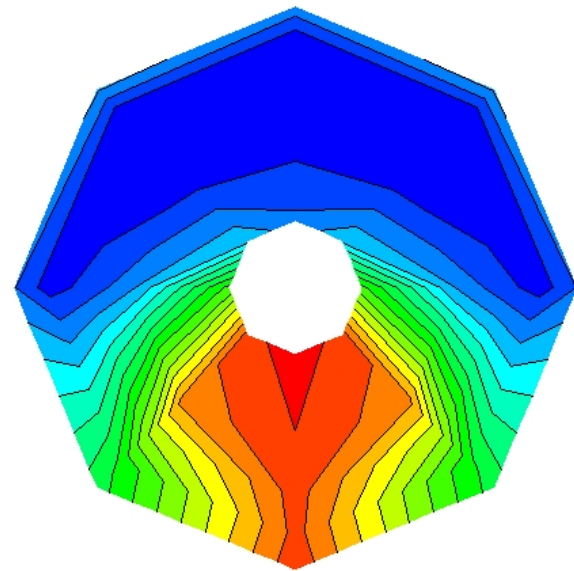

(d) Present CFD-2 $\left(\operatorname{Re}_{\mathrm{D}}=3.8 \mathrm{M}\right)$

Fig.A5 Comparison of total pressure contours at $\mathrm{AIP}\left(\mathrm{M}_{\infty}=\mathbf{0 . 8 5}\right)$

(See Fig. A3 for definitions of CFD-1 and CFD-2)

\section{Acknowledgements}

The authors are grateful for the support by the NASA’s Subsonic Fixed Wing Project of Fundamental Aeronautics Program.

\section{References}

${ }^{1}$ NASA Research and Technology Program and Project Management Requirements, NASA Procedural Requirements 7120.9. Appendix J. Technology Readiness Levels (TRLs), February 05, 2008.

${ }^{2}$ Liebeck, R. H., "Design of the Blended Wing Body Subsonic Transport," J. Aircraft, Vol. 41, No. 1, January-February 2004.

${ }^{3}$ Kawai, R. and Brown, D., “Acoustic Prediction Methodology and Test Validation for an Efficient Low-Noise 
Hybrid Wing Body Subsonic Transport," Phase I Final Report PWDM08-006A, NASA Contract Number NNL07AA54C, October, 2008.

${ }^{4}$ Hileman, J. I, Spakovszky, Z. S., Drela, M., Sargeant, M. A., Jones, A., “Airframe Design for Silent Fuel-Efficient Aircraft,” J. Aircraft, vol.47, No.3, May-June 2010, pp. 956-969. See also AIAA Paper 2007-453, Jan., 2007.

${ }^{5}$ de la Rosa Blanca, E., Hall, C. A., and Crichton, D., “Challenges in the Silent Aircraft Engine Design,” AIAA Paper 2007-454, Jan., 2007.

${ }^{6}$ Tong, M., Jones, S. M., Haller, W. J., and Handschuh, R. F., “Engine Conceptual Design Studies for a Hybrid Wing Body Aircraft," NASA/TM-2009-215680, November 2009. Appears also in Turbo Expo 2009, ASME, Orlando, FL, June 8-12, 2009.

${ }^{7}$ NASA-Industry Cooperative Effort, "Numerical Propulsion System Simulation User Guide and Reference," Software Release NPSS 1.5.0, May 7, 2002.

${ }^{8}$ Litle, J. K., “Numerical Propulsion System Simulation: An Overview,” NASA/TM-2000-209915.

${ }^{9}$ Kim, H., Kumano, T., Liou, M.-S., Povinelli, L. A., and Conners, T., "Numerical Propulsion Flow Simulation of Supersonic Inlet with Bypass Annular Duct,” J. Propulsion and Power, Vol.27, No.1, January-February 2011. pp. 29-39.

${ }^{10}$ Freuler, P., “Boundary layer ingestion inlet design for a silent aircraft,” MS thesis, MIT, 2005.

${ }^{11}$ Menter, F.R, “Two-Equation Eddy-Viscosity Turbulence Models for Engineering Applications,” AIAA J., Vol.32, No.8, August 1994, pp.1598-1605.

${ }^{12}$ Spalart, P. R. and Rumsey, C., "Effective Inflow Conditions for Turbulence Models in Aerodynamic Calculations," AIAA J., Vol.45, No.10, October 2007, pp.2544-2553.

${ }^{13}$ Sharov, D. and Nakahashi, K. "Reordering of Hybrid Unstructured Grids for Lower-Upper Symmetric Gauss-Seidel Computations,” AIAA J., Vol.36, No.3, pp.484-486, 1998.

${ }^{14}$ Ito, Y. and Nakahashi, K., "Direct Surface Triangulation Using Stereolithography Data," AIAA J., Vol. 40, No. 3, March 2002, pp. 490-496.

${ }^{15}$ Ito, Y., Shih, A. M., Soni, B. K. and Nakahashi, K., "Multiple Marching Direction Approach to Generate High Quality Hybrid Meshes," AIAA J., Vol. 45, No. 1, January 2007, pp. 162-167.

${ }^{16}$ Felder, J., Kim, H. D., and Brown, G. V., "An Examination of the Effects of Boundary Layer Ingestion on Turboelectric Distributed Propulsion Systems," AIAA 2011-300, 49 ${ }^{\text {th }}$ AIAA Aerospace Science Meeting, January 2011, Orlando, FL.

${ }^{17}$ Owens, L. R., Allan, B. G., and Gorton, S. A., " Boundary-Layer-Ingesting Inlet Flow Control," J. Aircraft, Vol. 45, No.4, July-August 2008, pp. 1431-1440.

${ }^{18}$ Lee, B. J., Liou, M.-S., and Kim, C., "Optimizing a Boundary-Layer-Ingesting Offset Inlet by Discrete Adjoint Approach," AIAA J., Vol. 48, No.9, September 2010, pp. 2008-2016.

${ }^{19}$ Allan, B. G. and Owens, L. R., "Numerical Modeling of Flow Control in a Boundary-Layer-Ingesting Offset Inlet Diffuser at Transonic Mach Numbers," AIAA 2006-0845, $44^{\text {th }}$ AIAA Aerospace Science Meeting, January 2006, Reno, NV.

${ }^{20}$ Johnson, B. C., Webster, R. S., and Sreenivas, K., "A Numerical Investigation of S-Duct Flows with Boundary-Layer Ingestion," AIAA 2010-0841, 48 ${ }^{\text {th }}$ AIAA Aerospace Science Meeting, January 2006, Orlando, FL.

${ }^{21}$ Gas Turbine Engine Inlet Flow Distortion, Society of Automotive Engineers, Rept. ARP-1420, March 1978. 